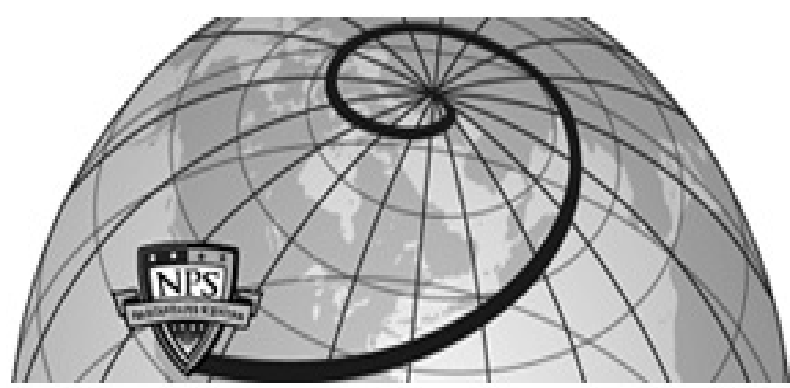

Calhoun: The NPS Institutional Archive DSpace Repository

\title{
Analysis of the effects of Marine Corps M1A1 Abrams tank age on operational availability
}

Scruggs, Andrew M.; Welch, Ryan P.

Monterey, California: Naval Postgraduate School

https://hdl.handle.net/10945/42724

This publication is a work of the U.S. Government as defined in Title 17, United States Code, Section 101. Copyright protection is not available for this work in the United States.

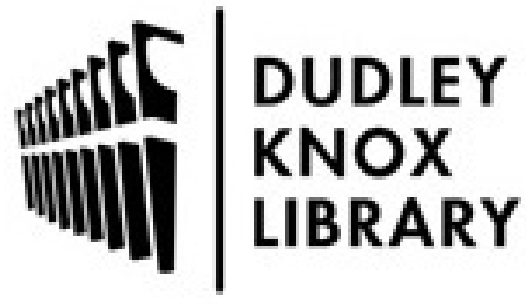

http://www.nps.edu/library
Calhoun is the Naval Postgraduate School's public access digital repository for research materials and institutional publications created by the NPS community. Calhoun is named for Professor of Mathematics Guy K. Calhoun, NPS's first appointed -- and published -- scholarly author.

Dudley Knox Library / Naval Postgraduate School 411 Dyer Road / 1 University Circle Monterey, California USA 93943 


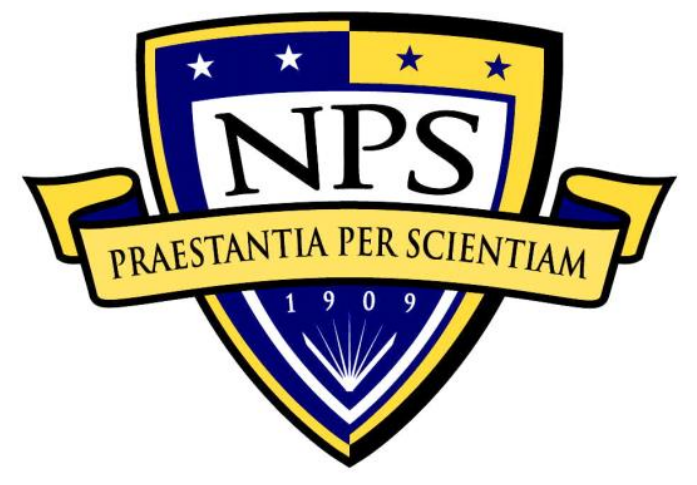

\section{NAVAL \\ POSTGRADUATE SCHOOL}

MONTEREY, CALIFORNIA

\section{ANALYSIS OF THE EFFECTS OF MARINE CORPS M1A1 ABRAM'S TANK AGE ON OPERATIONAL AVAILABILITY}

\section{By: Andrew M. Scruggs \\ Ryan P. Welch \\ June 2014}

Advisors: $\quad$ Brad Naegle

Keebom Kang 
THIS PAGE INTENTIONALLY LEFT BLANK 
Public reporting burden for this collection of information is estimated to average 1 hour per response, including the time for reviewing instruction, searching existing data sources, gathering and maintaining the data needed, and completing and reviewing the collection of information. Send comments regarding this burden estimate or any other aspect of this collection of information, including suggestions for reducing this burden, to Washington headquarters Services, Directorate for Information Operations and Reports, 1215 Jefferson Davis Highway, Suite 1204, Arlington, VA 22202-4302, and to the Office of Management and Budget, Paperwork Reduction Project (0704-0188) Washington DC 20503.

\begin{tabular}{|l|c|c|}
\hline 1. AGENCY USE ONLY (Leave blank) & $\begin{array}{c}\text { 2. REPORT DATE } \\
\text { June } 2014\end{array}$ & $\begin{array}{c}\text { 3. REPORT TYPE AND DATES COVERED } \\
\text { MBA Professional Report }\end{array}$ \\
\hline
\end{tabular}

\begin{tabular}{l|l} 
4. TITLE AND SUBTITLE & 5. FUNDING NUMBERS
\end{tabular}

ANALYSIS OF THE EFFECTS OF MARINE CORPS M1A1 ABRAM'S TANK

AGE ON OPERATIONAL AVAILABILITY

6. AUTHOR(S) Andrew M. Scruggs and Ryan P. Welch

7. PERFORMING ORGANIZATION NAME(S) AND ADDRESS(ES)

Naval Postgraduate School

Monterey, CA 93943-5000

9. SPONSORING /MONITORING AGENCY NAME(S) AND ADDRESS(ES)

N/A

8. PERFORMING ORGANIZATION REPORT NUMBER

10. SPONSORING/MONITORING AGENCY REPORT NUMBER

11. SUPPLEMENTARY NOTES The views expressed in this thesis are those of the author and do not reflect the official policy or position of the Department of Defense or the U.S. Government. IRB Protocol number

12a. DISTRIBUTION / AVAILABILITY STATEMENT N/A

Approved for public release; distribution is unlimited

12b. DISTRIBUTION CODE

\section{ABSTRACT (maximum 200 words)}

The M1A1 Abram's Main Battle Tank (MBT) is expected to remain a key piece of USMC equipment beyond 2025. Because the majority of equipment life-cycle costs occur in the operations and support phase, it is imperative that program managers incorporate effective and efficient product support strategies, balancing costs and reliability to create value for the government. The purpose of this project is to determine the effects of age, as measured by the time since the last depot-level rebuild, on equipment operational availability for the M1A1 MBT in the Marine Corps. Our study includes an overview of the history of M1A1 development, Department of Defense materiel maintenance policy, M1A1 rebuild strategy, and prior M1A1 reliability studies. We reviewed depot- and unit-level maintenance records within the USMC's System Operational Effectiveness database to establish a correlation between years since last rebuild and operational availability (Ao). The objective of our research is to quantify the age-related effects on Ao to better inform the decision-making process of USMC leadership in determining materiel maintenance strategies.

14. SUBJECT TERMS M1A1 Abrams MBT, Reliability Centered Maintenance (RCM), Operational Availability, Materiel Maintenance, Anniston Army Depot, Depot-Level Maintenance

15. NUMBER OF PAGES 67 16. PRICE CODE

17. SECURITY CLASSIFICATION OF REPORT Unclassified Unclassified
18. SECURITY CLASSIFICATION OF THIS PAGE Unclassified

19. SECURITY
CLASSIFICATION OF
ABSTRACT

ABSTRACT Unclassified
20. LIMITATION OF ABSTRACT

UU

Standard Form 298 (Rev. 2-89) Prescribed by ANSI Std. 239-18 
THIS PAGE INTENTIONALLY LEFT BLANK 
Approved for public release; distribution is unlimited

\title{
ANALYSIS OF THE EFFECTS OF MARINE CORPS M1A1 ABRAM'S TANK AGE ON OPERATIONAL AVAILABILITY
}

\author{
Andrew M. Scruggs, Captain, United States Army \\ Ryan P. Welch, Captain, United States Army \\ Submitted in partial fulfillment of the requirements for the degree of \\ MASTER OF BUSINESS ADMINISTRATION
}

from the

NAVAL POSTGRADUATE SCHOOL

June 2014

Authors: $\quad$ Andrew M. Scruggs

Ryan P. Welch

Approved by: $\quad$ Brad Naegle

Keebom Kang

William R. Gates, Dean

Graduate School of Business and Public Policy 
THIS PAGE INTENTIONALLY LEFT BLANK 


\title{
ANALYSIS OF THE EFFECTS OF MARINE CORPS M1A1 ABRAM'S TANK AGE ON OPERATIONAL AVAILABILITY
}

\begin{abstract}
The M1A1 Abram's Main Battle Tank (MBT) is expected to remain a key piece of USMC equipment beyond 2025. Because the majority of equipment life-cycle costs occur in the operations and support phase, it is imperative that program managers incorporate effective and efficient product support strategies, balancing costs and reliability to create value for the government. The purpose of this project is to determine the effects of age, as measured by the time since the last depot-level rebuild, on equipment operational availability for the M1A1 MBT in the Marine Corps. Our study includes an overview of the history of M1A1 development, Department of Defense materiel maintenance policy, M1A1 rebuild strategy, and prior M1A1 reliability studies. We reviewed depot- and unit-level maintenance records within the USMC's System Operational Effectiveness database to establish a correlation between years since last rebuild and operational availability $\left(\mathrm{A}_{\mathrm{o}}\right)$. The objective of our research is to quantify the age-related effects on $A_{o}$ to better inform the decision-making process of USMC leadership in determining materiel maintenance strategies.
\end{abstract}


THIS PAGE INTENTIONALLY LEFT BLANK 


\section{TABLE OF CONTENTS}

I. INTRODUCTION .1

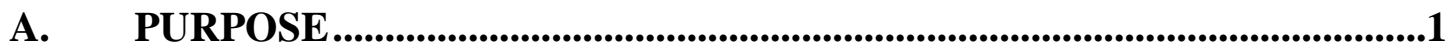

B. REPORT SUMMARY ..............................................................................1

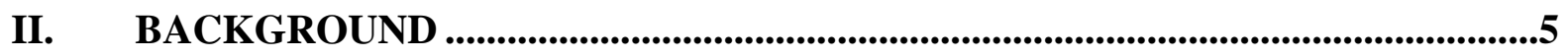

A. M1A1 ACQUISITION AND DEVELOPMENT HISTORY .....................5

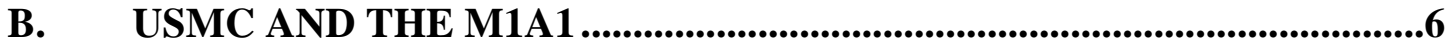

C. USMC M1A1 MISSION................................................................................6

D. D. USMC M1A1 FORCE STRUCTURE ................................................7

E. MARINE CORPS GROUND EQUIPMENT MAINTENANCE

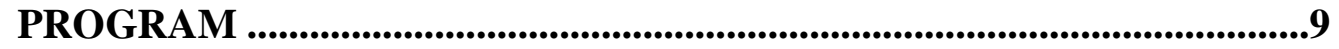

1. Field-Level Maintenance ..........................................................................99

a. Organizational-Level Maintenance.......................................9

b. Intermediate-Level Maintenance ........................................10

2. Depot-Level Maintenance ................................................................10

F. MATERIEL READINESS .........................................................................11

G. RELIABILITY-CENTERED MAINTENANCE ........................................11

H. RELIABILITY-CENTERED MAINTENANCE HISTORY ....................12

I. DOD POLICY AND RELIABILITY-CENTERED MAINTENANCE ...14

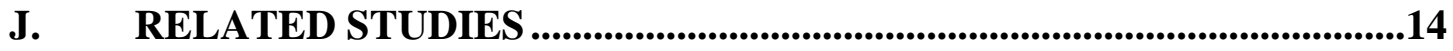

K. M1A1 MBT REBUILD PLANNING, PROGRAMMING, BUDGETING, AND EXECUTION ......................................................16

L. ANNISTON ARMY DEPOT ...................................................................17

M. M1A1 MBT REBUILD STRATEGY ........................................................18

N. STATEMENT OF WORK FOR M1A1 REBUILD ...................................18

O. RELEVANCE OF M1A1 REBUILD PROGRAM TO DOD LOGISTICS CAPABILITY ................................................................20

III. RESEARCH METHODOLOGY .....................................................................21

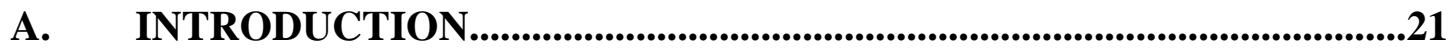

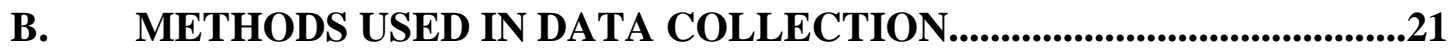

1. Qualitative Data ..........................................................................21

2. Quantitative Data....................................................................................21

C. DATA COLLECTION QUESTIONS................................................................22

1. Tank Age....................................................................................22

2. Applicable USMC Regions..................................................................22

3. Operational Availability ...................................................................23

4. Exclusion of Observations .......................................................................23

D. ANALYTICAL PROCESS .....................................................................24

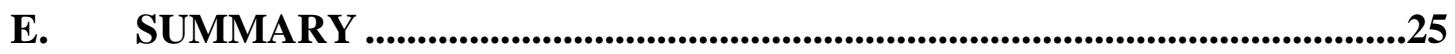

IV. RESULTS AND ANALYSIS ...................................................................................27

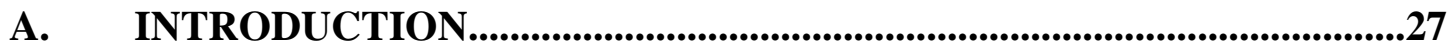

B. M1A1 OPERATIONAL AVAILABILITY BY AGE ..............................27 


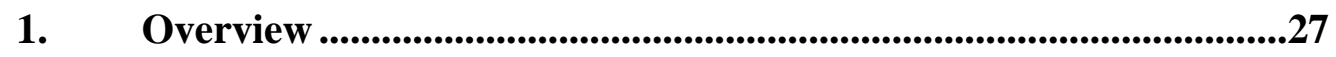

2. Data Collection ...........................................................................................27

3. Age of Tanks ..................................................................................28

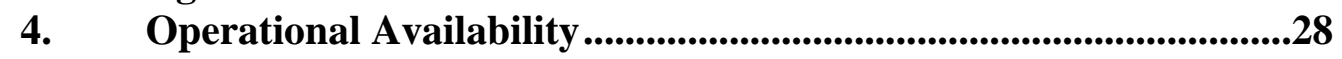

5. Age and Operational Availability Correlation................................29

6. Analysis ..........................................................................................................30

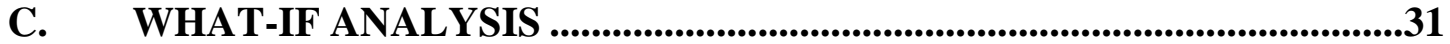

1. Overview ...............................................................................................31

2. Data Collection ............................................................................................31

3. Average Age Forecast ....................................................................31

4. Combat Power Comparison ........................................................33

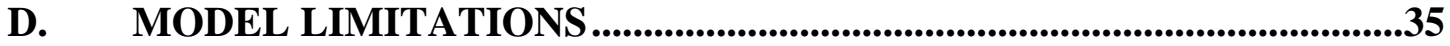

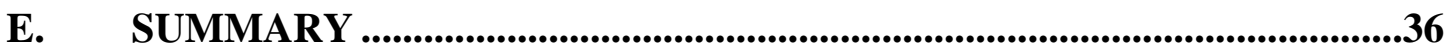

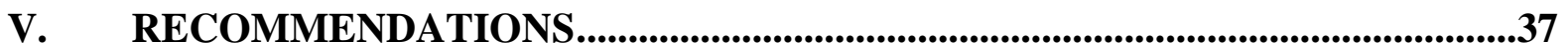

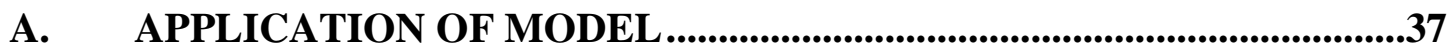

1. Depot-Maintenance Planning .....................................................37

2. Tank-Deployment Selection ...........................................................37

B. FURTHER RESEARCH.......................................................................37

APPENDIX A. USMC M1A1 MBT SPECIFICATIONS ...............................................39

APPENDIX B. SYSTEM OPERATIONAL EFFECTIVENESS ASSUMPTIONS ........41

APPENDIX C. SYSTEM OPERATIONAL EFFECTIVENESS FIELD DEFINITIONS ..........................................................................................................................45

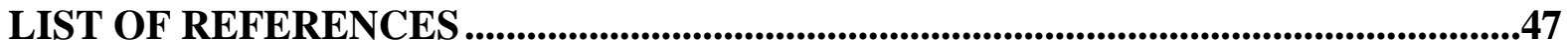

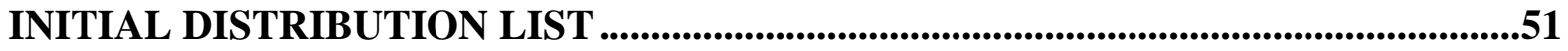




\section{LIST OF FIGURES}

Figure 1. Cutaway Drawing of M1A1 MBT Showing Position of Main Components (from Jane's Information Group, 2013)....

Figure 2. Rotational Diagram of USMC M1A1 MBTs (from MARCORSYSCOM [PM Tank Systems], 2013) ................................................................

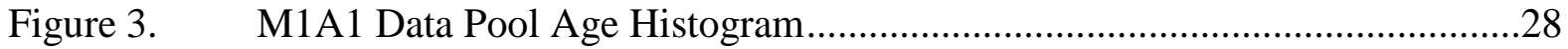

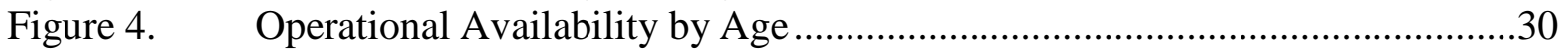

Figure 5. Quantity of Tanks by Age in 2013 ..........................................................32

Figure 6. USMC M1A1 Forecasted Age Through 2035 by Rebuild Level ...................33

Figure 7. USMC M1A1 Forecasted $A_{o}$ Through 2035 by Rebuild Level.......................34 
THIS PAGE INTENTIONALLY LEFT BLANK 


\section{LIST OF TABLES}

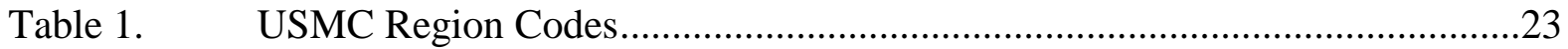

Table 2. Compiled Tank Data ..........................................................................29 
THIS PAGE INTENTIONALLY LEFT BLANK 


\section{LIST OF ACRONYMS AND ABBREVIATIONS}

\begin{tabular}{|c|c|}
\hline $\mathrm{AAO}$ & approved acquisition objective \\
\hline AGT & advanced gas turbine \\
\hline AMC & Army Materiel Command \\
\hline AMT & active maintenance time \\
\hline ANAD & Anniston Army Depot \\
\hline $\mathrm{A}_{\mathrm{o}}$ & operational availability \\
\hline CASC & Capabilities Assessment Support Center \\
\hline $\mathrm{CC}$ & critical code \\
\hline CBM & condition-based maintenance \\
\hline CITE & center of industrial and technical excellence \\
\hline CVE & combat vehicle evacuation \\
\hline DCD & deadline control date \\
\hline DFMA & depot float maintenance allowance \\
\hline DOD & Department of Defense \\
\hline DODD & Department of Defense Directive \\
\hline DODI & Department of Defense Instruction \\
\hline $\mathrm{ECP}$ & engineering change proposals \\
\hline $\mathrm{EFC}$ & equivalent full charge \\
\hline ELMP & enterprise-level maintenance program \\
\hline ERO & equipment repair orders \\
\hline FAA & Federal Aviation Administration \\
\hline FEP & firepower enhancement program \\
\hline FMC & full mission capable \\
\hline FY & fiscal year \\
\hline GAO & Government Accountability Office \\
\hline GCE & ground combat element \\
\hline HQMC & Headquarters United States Marine Corps \\
\hline IDN & item designator number \\
\hline IROAN & inspect and repair only as necessary \\
\hline ISO & International Standards Organization \\
\hline KPP & key performance parameter \\
\hline KSA & key system attribute \\
\hline LCR & last complete rebuild \\
\hline LOM & levels of maintenance \\
\hline LRT & logistics response time \\
\hline LTI & limited technical inspection \\
\hline MARADMIN & Marine Administrative Message \\
\hline MARCORSYSCOM & Marine Corps Systems Command \\
\hline MAGTF & Marine Air-Ground Task Force \\
\hline MBT & main battle tank \\
\hline MCLB & Marine Corps Logistics Base \\
\hline MCWP & Marine Corps Warfighting Publication \\
\hline
\end{tabular}




MDBM
MDT
MEF
MIL-HDBK
MIL-STD
MPF
MPS
MR
MSC
MSG
NAVAIR
NIIN
NSN
NTC
O\&S
OASA(AL\&T)
OR
OUSD(AT\&L)
OUSD(L\&MR)
PHS\&T
PPBE
RCM
SAE
SOE
SOW
TACOM
TFSMS
TI
TLCM
TMDE
UCF
U.S.C.
USMC
UTC
WSTIAC
OASA

mean downtime between maintenance

maintenance downtime

Marine Expeditionary Force

military handbook

military standard

maritime prepositioning force

maritime prepositioning ship

materiel readiness

Military Sealift Command

maintenance steering group

United States Navy Air Systems Command

national item identification number

national stock number

National Training Center

operations and support

Office of the Assistant Secretary of the Army for Acquisition, Logistics, and Technology

Operational Readiness

Office of the Under Secretary of Defense for Acquisition, Logistics, and Technology

Office of the Under Secretary of Defense for Logistics and Materiel Readiness

packaging, handling, storage, and transportation

planning, programing, budgeting, and execution

reliability centered maintenance

Society of Automotive Engineers

System Operational Effectiveness

statement of work

Tank-Automotive and Armaments Command

Total Force Structure Management System

technical instruction

total life cycle management

test, measurement, and diagnostic equipment

unit cost fund

United States Code

United States Marine Corps

unit total cost

Weapon Systems Technology Information Analysis Center 


\section{INTRODUCTION}

In the Department of Defense (DOD), program (product) managers within the acquisition community have the responsibility to deliver required warfighter capabilities and sustain those capabilities through the product life cycle. The operations and support $(\mathrm{O} \& \mathrm{~S})$ phase of the defense acquisition life-cycle management system represents the longest duration period of the weapon system life cycle and constitutes $60-70 \%$ of lifecycle cost (Office of the Under Secretary of Defense for Logistics and Materiel Readiness [OUSD(L\&MR)], 2011, p. 67). The United States Marine Corps (USMC) M1A1 Abrams Tank entered the O\&S phase in 1989 when initially fielded. The M1A1 is expected to remain a key piece of USMC equipment beyond 2025, representing a 36-year time period within the O\&S phase. Because the majority of life-cycle costs occur in the O\&S phase, it is imperative that program managers incorporate effective and efficient product support strategies balancing costs and reliability to create value for the government.

\section{A. PURPOSE}

The purpose of this project is to determine the effects of age, as measured by the time since the last depot-level rebuild, on equipment operational availability for the M1A1 Main Battle Tank (MBT) in the Marine Corps. Our study includes an overview of the history of M1A1 development, DOD materiel maintenance policy, M1A1 rebuild strategy, and prior M1A1 reliability studies. We reviewed depot- and unit-level maintenance records within the USMC's System Operational Effectiveness (SOE) database to establish a correlation between years since last rebuild and operational availability $\left(\mathrm{A}_{\mathrm{o}}\right)$. The objective of our research is to quantify the age-related effects on $\mathrm{A}_{\mathrm{o}}$ to better inform the decision-making process of USMC leadership in determining materiel maintenance strategies.

\section{B. REPORT SUMMARY}

We collected qualitative data from DOD publications, Navy and Marine Corps publications, and documents supplied by the USMC M1A1 program office to describe 
the USMC's M1A1 MBT rebuild and employment strategy. We examined the M1A1 $\mathrm{A}_{\mathrm{o}}$ using a six-year history, 2008-2013, from the USMC's SOE application to acquire data on the M1A1, specifically the annual downtime and uptime per tank by serial number. This online application uses data from numerous USMC data sources in order to compile a comprehensive repository of operational effectiveness data regarding USMC weapons systems. With this data, we calculated the average $\mathrm{A}_{\mathrm{o}}$ by tank age through each of the six years of SOE data.

We determined the correlation between operational availability and age in conjunction with calculating the average age of the tanks in our data pool. This report defines age of a tank as the elapsed time since its last complete rebuild (LCR) at the Anniston Army Depot (ANAD). In our analysis for this project, we used a simple linear regression model to determine a correlation between the dependent variable, $\mathrm{A}_{0}$, and the explanatory variable, age. This allowed us to determine the true significance of tank age as previously defined in relation to M1A1 availability to the USMC fleet. Based on our quantitative analysis, our model predicts that each tank will decrease in $A_{o}$ by .0138 each year it gets older.

Our regression model is a valuable tool that can be used to determine the link between age and $A_{o}$ for the USMC M1A1 MBT fleet. Our R-squared value of .743 indicates that there is a fairly strong correlation between the age of the tanks and their $\mathrm{A}_{0}$. This correlation does not mean age is the cause of the degradation in availability, rather, it is an indicator used to forecast availability.

Applying the correlation between age and $\mathrm{A}_{\mathrm{o}}$, we conducted a what-if analysis comparing M1A1 fleet strength over time given different annual rebuild quantities. In 2013, the average age of the M1A1 fleet was 4.49 years, with the oldest tank being nine years since its last rebuild. We used rebuild levels from 30 to 40 tanks per year and forecasted out to the year 2035, the expected life of the USMC M1A1. Given this constant process for rebuild, each level of rebuild reached an equilibrium state where the average age of the tanks remains constant. This occurred between 2023 at 40 tanks per year and 2027 with 30 tanks per year. At these rebuild levels, the most significant difference between $A_{0}$, again in 2027 between 40 tanks per year and 30 tanks per year, 
was .0258 in 2027. As a result, the net difference in average full mission capable (FMC) tanks based on $\mathrm{A}_{\mathrm{o}}$ between these two rebuild levels is 2.32 FMC M1A1s in 2015 and 10.28 FMC M1A1s in 2027 at an approved acquisition objective (AAO) of 399 tanks. 
THIS PAGE INTENTIONALLY LEFT BLANK 


\section{BACKGROUND}

The M1 series Main Battle Tank (MBT) is a key piece of equipment for the United States military in conducting offensive and defensive operations. The Army M1 MBT program dates back to the early 1970s with the XM1 tank and evolved into the M1A1 in the late 1980s with upgraded armor and $120 \mathrm{~mm}$ gun tube. The USMC received its first units of M1A1 MBTs in 1989, and additional tanks were transferred to the USMC from the Army and Anniston Army Depot through 2008. The following sections of this background chapter describe the acquisition and development history of the M1A1 MBT, the role and force structure of the M1A1 MBT within the USMC, an overview of USMC ground equipment maintenance, the DOD maintenance policy, and the USMC M1A1 rebuild program.

\section{A. M1A1 ACQUISITION AND DEVELOPMENT HISTORY}

The Army's M1 MBT program began in December 1971, leading to the award of two prototype development contracts in 1973. The Army awarded one of the two contracts, valued at $\$ 68.1$ million, to the defense division of the Chrysler Corporation (now General Dynamics Land Systems) and the other contract, valued at \$88 million, to the Detroit Diesel Allison Division of the General Motors Corporation (Jane's Information Group, 2013). In February 1976, the Army accepted both prototypes for test and evaluation, and in November, the secretary of the Army announced that the Chrysler Corporation prototype had been selected for full-scale development and production (Jane's Information Group, 2013). By 1982, M1 tanks were in full-rate production at both the Detroit Arsenal Tank Plant in Michigan and Lima Army Tank Plant in Ohio. Production facilities were initially operated by Chrysler, but in 1982 Chrysler sold its production subsidiary (Chrysler Defense Incorporated) to General Dynamics (Jane's Information Group, 2013).

The M1 tank program continued to evolve, receiving upgraded armor and a 120 mm main gun, leading to the M1A1. In 1987, the Army's Tank-Automotive and Armaments Command (TACOM) issued a $\$ 3.5$ billion multi-year contract to General 
Dynamics Land Systems to produce 3,299 M1A1 tanks (Jane's Information Group, 2013). Production of the M1A1 ceased in April 1993, culminating with General Dynamics Land Systems producing a total of 4,796 M1A1 tanks at the Lima and Detroit tank plants (Jane's Information Group, 2013).

\section{B. USMC AND THE M1A1}

In 1989, the USMC procured 221 M1A1 MBTs and received its first shipment of tanks in November 1989. The USMC, in 1995, procured 50 additional tanks from Anniston Army Depot in Alabama. While still at the Anniston Army Depot, all 50 tanks received a total of 62 modifications to match the configuration of the previously acquired 221 M1A1 MBTs (Jane's Information Group, 2013). Also in 1995, the Army transferred an additional 132 M1A1 MBTs to the Marines, bringing the USMC on-hand allocation to 403. The USMC continued to modernize the M1A1 fleet with the firepower enhancement program (FEP), which consisted of thermal sights, imaging resolution, target range, and detection capability sight upgrades (Jane's Information Group, 2013). By fiscal year (FY) 2009, the entire fleet received FEP upgrades. In 2008, the USMC received an additional $44 \mathrm{M} 1 \mathrm{~A} 1 \mathrm{MBTs}$ when each of the two active-duty tank battalions force structures increased by one additional tank company to respond to overseas contingency operation requirements (Jane's Information Group, 2013). ${ }^{1}$

\section{USMC M1A1 MISSION}

The M1A1 Abrams MBT was designed primarily as an offensive weapon but is also an effective defensive weapon system. The mission of the M1A1 is to "close with and destroy the enemy by using armor-protected firepower, shock effect, and maneuver, and to provide anti-mechanized fire in support of the Marine division" (Headquarters United States Marine Corps [HQMC], 2005, p. 1-1). Speed, mobility, armor-protective

\footnotetext{
${ }^{1}$ Of the 44 M1A1 tanks received, 24 tanks equipped the additional tank companies and 16 were reserved as maintenance float vehicles. Maintenance float vehicles are a pool of available assets that can be transferred to operational units when the operational unit has an unexpected decrease in readiness because of maintenance activities.
} 
fire power, and shock effect are the core capabilities the MBT provides to the Marine Air-Ground Task Force (MAGTF) and ground combat element (GCE) commanders, ensuring superior combat power to achieve decisive results on the battlefield (HQMC, 2005). Figure 1 illustrates the main components of a M1A1 MBT, including location of military personnel. Current specifications of the USMC M1A1 MBT are in Appendix 1.

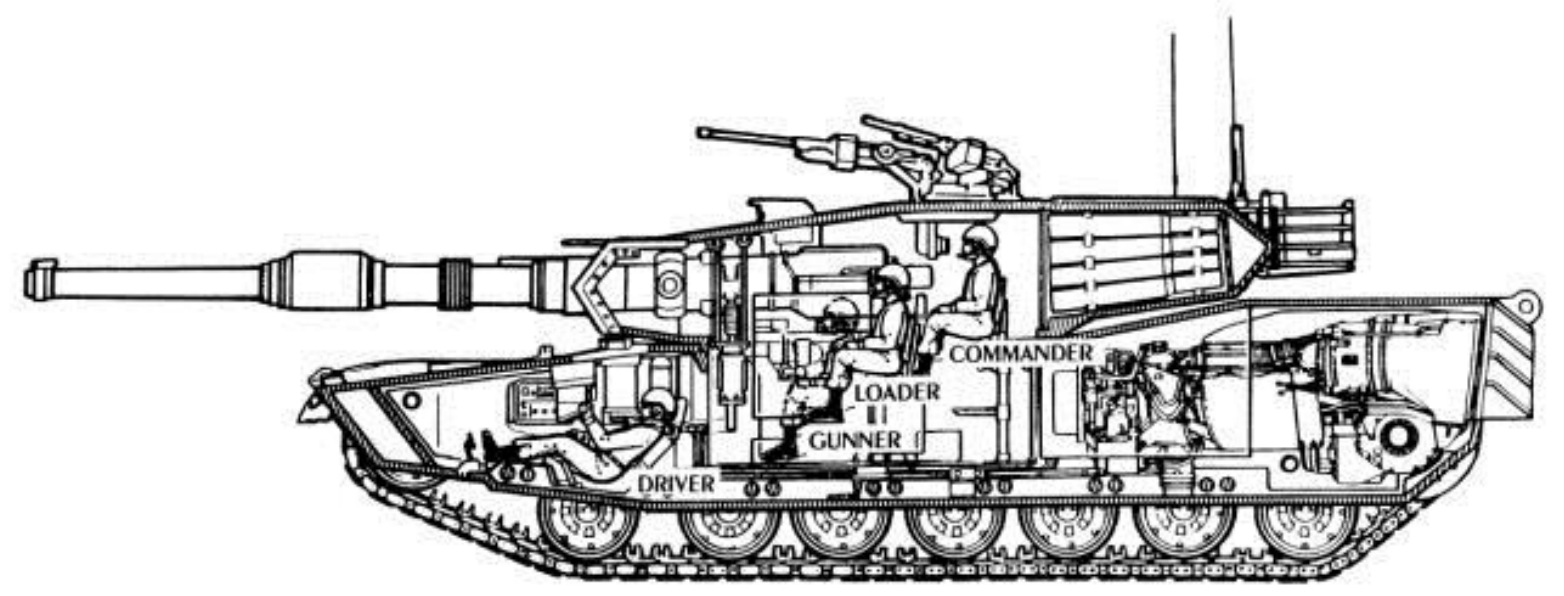

Figure 1. Cutaway Drawing of M1A1 MBT Showing Position of Main Components (from Jane's Information Group, 2013)

\section{D. USMC M1A1 FORCE STRUCTURE}

Currently, the USMC has a total force structure management system (TFSMS) approved acquisition objective (AAO) of 399 M1A1 MBTs and a depot float maintenance allowance (DFMA) of up to 43 M1A1 MBTs (TACOM, 2013). The purpose of the DFMA is to ensure mission-essential equipment availability for operational forces while tanks are in transit to and from the depot (MARCORSYSCOM [PM Tank Systems], 2012). Figure 2 depicts the normal rotation for an M1A1. 


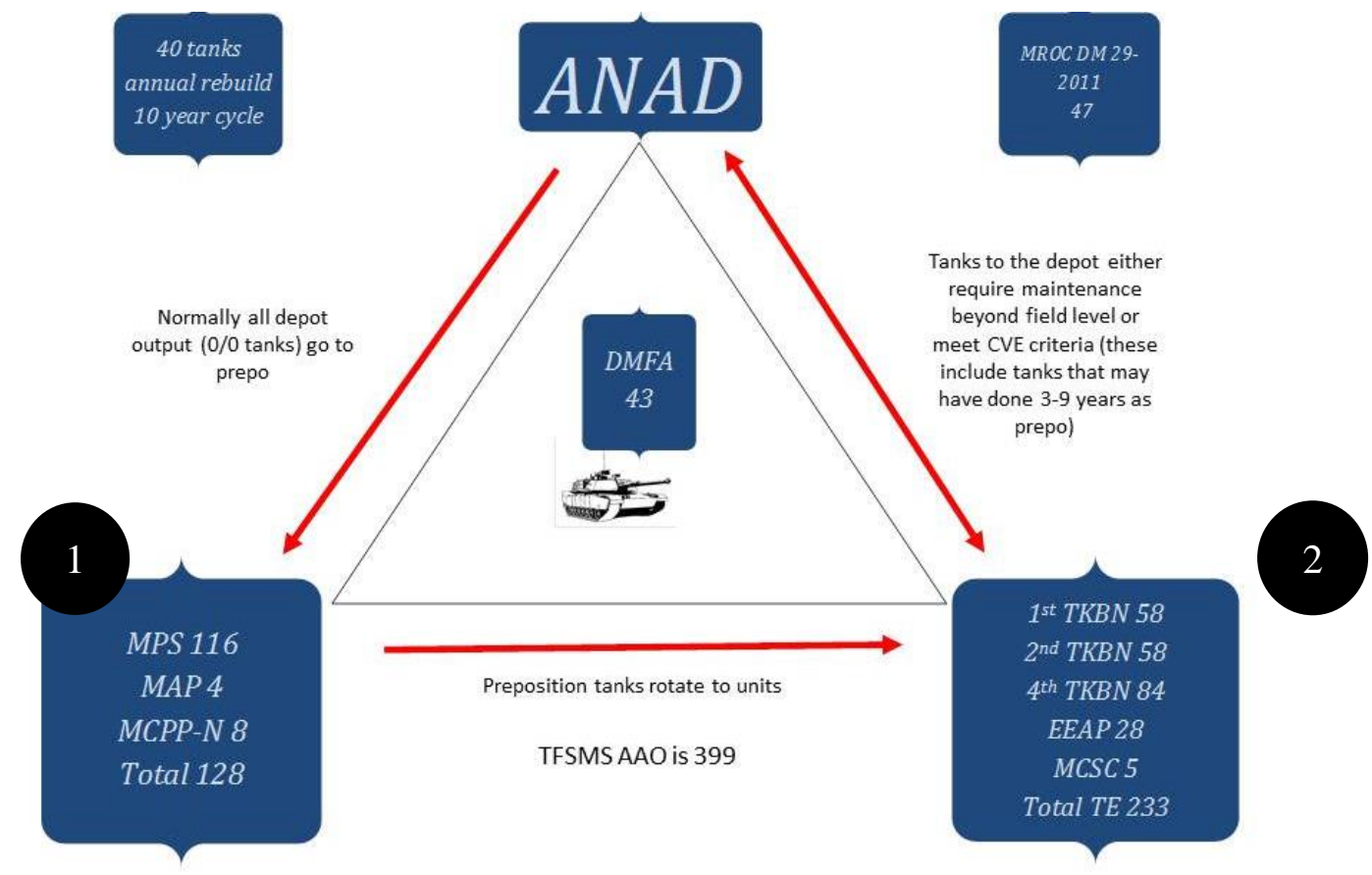

Figure 2. Rotational Diagram of USMC M1A1 MBTs (from MARCORSYSCOM [PM Tank Systems], 2013)

The priority after a tank is overhauled at Anniston Army Depot (ANAD) is to send it to the maritime prepositioning force (MPF), which is identified by the number one in Figure 2. According to the Navy's Military Sealift Command (2013) website, the MPF "strategically places military equipment and supplies aboard ships located in key ocean areas to ensure rapid availability during a major theater war, a humanitarian operation or other contingency." While on these preposition ships, the tanks have zero or minimal usage and sporadic visual inspections due to the limited storage area. These tanks are on a ship for three to nine years before being transferred to an operational unit, which is identified by the number two in Figure 2. While at the units, the tanks are utilized in accordance with the USMC M1A1 strategic mission. Currently, the USMC rotates, on average, $40 \mathrm{M} 1 \mathrm{~A} 1 \mathrm{MBT}$ annually from operational units to the ANAD for a complete rebuild. Operational units then receive tanks from the MPF, if available, or newly rebuilt tanks from the ANAD. 


\section{E. MARINE CORPS GROUND EQUIPMENT MAINTENANCE PROGRAM}

DOD Directive 4151.18, Maintenance of Military Materiel (OUSD[L\&MR], 2004), provides overarching policy and guidance for executing DOD maintenance activities. The OUSD is responsible for establishing DOD maintenance policy and guidance; however, the three service secretaries are directly responsible for equipping and maintaining their respective forces per 10 U.S.C. 3013 (Army), 10 U.S.C. 5013 (Navy), and 10 U.S.C. 8013 (Air Force).

Marine Administrative Message (MARADMIN) 159, released March 26, 2013, established the USMC's policy concerning the ground equipment maintenance program and instituted two levels of maintenance (LOM) known as "field" and "depot" (HQMC, 2013). Distinction between the two LOM are associated with the maintenance tasks and unit capabilities within each level.

\section{Field-Level Maintenance}

Field-level maintenance encompasses two echelons: organizational and intermediate. According to USMC policy, units are not authorized to perform maintenance tasks beyond their equipment and manning capabilities.

\section{a. Organizational-Level Maintenance}

Organizational-level maintenance can be generally described as on-equipment maintenance. Organizational-level maintenance is conducted at the unit level by both the equipment operator and unit maintenance personnel, and is centered on preventive and corrective actions necessary to sustain equipment in a mission capable status. MARADMIN 581, released December 15, 2003, describes preventive and corrective maintenance actions, which include inventory, cleaning, inspecting, preserving, lubricating, adjusting, testing, and replacing parts and components with basic mechanic tool sets (HQMC, 2003). 


\section{b. Intermediate-Level Maintenance}

Intermediate-level maintenance is shop-type maintenance to return equipment to a mission-capable status. Within the USMC, intermediate-level maintenance for the M1A1 MBT is conducted beyond the unit level at one of the two active duty maintenance battalions. MARADMIN 581 describes intermediate-level maintenance actions to include, but not be limited to, inspection, diagnosis, part or component replacement, precision machining, and welding, and also include calibration and repair of test, measurement, and diagnostic equipment (TMDE).

\section{Depot-Level Maintenance}

The USMC utilizes depot-level maintenance activities to sustain military equipment throughout the equipment's useful life cycle. Title 10 U.S.C. $\S 2460$ (2012) defines depot-level maintenance and repair:

Material maintenance or repair requiring the overhaul, upgrading, or rebuilding of parts, assemblies, or subassemblies, and the testing and reclamation of equipment as necessary, regardless of the source of funds for the maintenance or repair or the location at which the maintenance or repair is performed. ( $\$ 2460$ (a))

The USMC possesses two organic depot-level repair facilities, which are located at Marine Corps Logistics Base (MCLB) Albany, GA, and MCLB Barstow, CA. However, USMC organic depot-level capabilities are not used in support of the M1A1 MBT. Because of cost savings, the USMC stopped utilizing its depots at Albany and Barstow for M1A1 MBT rebuild and maintenance activities and shifted its depot-level workload to the ANAD in Alabama. Depot-level evacuation criteria for the M1A1 MBT was published in Technical Instruction (TI) 08953A-14/9, Enclosure 1, released in 1997 (USMC, 1997). M1A1 MBTs can be selected as a rebuild candidate based on the following criteria:

- $\quad$ The hours of operation, months in active use (combat or other), equivalent full charge (EFC) rounds fired, and miles traveled enable commanders and logistics managers to predict when the M1A1 will become a candidate for the combat vehicle evacuation (CVE) program. Thresholds for hours of operation, months in active service, and EFC are 3,000, 300, and 750, respectively. 
- A candidate selected on the basis of "months in active use" will be qualified by a limited technical inspection (LTI) in accordance with current M1A1 inspection standards.

- $\quad$ M1A1s meeting the EFC rounds fired criteria will be nominated for the CVE program regardless of LTI results.

- When an LTI shows that an M1A1 requires repair beyond field-level capability, it will be reported as a candidate.

- When an LTI shows that an M1A1 requires field-level repair but will require extensive man-hours or considered to be an economical drain on the using units operational budget to bring it back to a serviceable condition, this tank should be considered as a candidate for the CVE program. (USMC, 1997, p. 2)

\section{F. MATERIEL READINESS}

One of the most important metrics for measuring the success of major acquisition program within the DOD is materiel reliability. All acquisition programs must have materiel availability as a key performance parameter (KPP) and materiel reliability as a key system attribute (KSA), according to the OUSD(L\&MR; 2012). These metrics, while important in developing requirements for a program, also translate to readiness reporting during the sustainment phase. The USMC uses a simple formula to determine the materiel readiness $(\mathrm{MR})$ rating percentage for a given unit:

$$
M R=\frac{\text { Equipment Possessed-Deadlined Equipment }}{\text { Equipment Authorized }}
$$

In Equation 1, deadlined equipment is defined as equipment that is "not mission capable and cannot perform its designated combat mission due to the need for critical repairs," according to the USMC (2012). The PM Tank System office continuously monitors this metric to identify M1A1 readiness trends to better develop sustainment plans.

\section{G. RELIABILITY-CENTERED MAINTENANCE}

The intent of maintenance is to ensure that a piece of equipment is capable of performing its required mission or purpose. Reliability-centered maintenance (RCM) is an applied process to determine what actions must be performed to ensure equipment 
continues to function as expected by the user (Moubray, 1997). More specifically, the DOD defines RCM as "a logical, structured process used to determine the optimal failure management strategies for any system, based on system reliability characteristics and the intended operating context" (Office of the Under Secretary of Defense for Acquisition, Technology, and Logistics [OUSD(AT\&L)], 2012b, p. 25).

$\mathrm{RCM}$ is a tool that can be applied throughout the equipment life cycle to assist decision-makers in determining cost-effective actions to promote maintenance efficiency and improve reliability. Failure management strategies range from engineering change proposals (ECPs), preventive maintenance requirements, technical manual modifications, and training programs to full-blown overhaul or rebuild programs (OUSD[AT\&L], $2012 \mathrm{~b}$ ). The goal of RCM is not to reduce failures, but to identify and implement maintenance-related solutions that avoid or reduce the consequences of failures (United States Navy Air Systems Command [NAVAIR], 2013).

\section{H. RELIABILITY-CENTERED MAINTENANCE HISTORY}

In the 1950s, maintenance planning was centered on the notion that equipment had a useful life, which led to the concept of preventive maintenance (Moubray, 1997). Thus, preventive maintenance strategies, such as overhauls, at fixed intervals were considered essential to maintain equipment reliability (Moubray, 1997). The airline industry in the 1960s performed periodic overhauls in its efforts to sustain the fleet but realized that its efforts were unsustainable (Nowlan \& Heap, 1978). As a result, the Federal Aviation Administration (FAA) and commercial airline industry formed a maintenance steering group (MSG) committee to analyze preventive maintenance programs. The committee published a handbook on maintenance evaluation and program development, known as MSG-1, which was used to develop the maintenance program on Boeing's 747 (Nowlan \& Heap, 1978).

In 1978, F. Stanley Nowlan and Howard F. Heap of United Airlines released Reliability-Centered Maintenance, which provided additional guidance and a systematic process to maintenance planning. Nowlan and Heap (1978) found that scheduled periodic overhaul has little effect on overall reliability unless there is a dominant failure 
mode present. The DOD sponsored Nowlan and Heath in their research and has incorporated RCM principles and processes into policy since the early 1980s.

The following time line describes the history of RCM evolution within DOD policy:

- $\quad$ DOD Directive 4151.16, DOD Equipment Maintenance Program (1984), requires RCM to be used as the basis for establishing and sustaining preventive maintenance programs for all DOD equipment (p. 1).

- $\quad$ DOD MIL-STD-2173(AS), Reliability Centered Maintenance Requirements for Naval Aircraft, Weapon Systems and Support Equipment (1986), provides procedures for conducting RCM analysis (p. 1). This publication supersedes MIL-HDBK-266(AS), published in 1981, which was one of the first DOD publications implementing RCM principles.

- $\quad$ GAO Report No. GAO/NSIAD-93-163, Depot Maintenance: Requirement to Update Maintenance Analyses Should Be Modified (1993), stated that military official believe "performing or updating RCM analyses on operational systems with extensive maintenance histories was not costeffective because the analyses are expensive to perform and would not significantly reduce maintenance requirements" (p. 2).

- $\quad$ The Society of Automotive Engineers (SAE) issued SAE JA1011, Evaluation Criteria for RCM Processes (1999), to serve as an industry standard to "evaluate any process that purports to be an RCM process, in order to determine whether it is a true RCM process" (p. 1).

- $\quad$ SAE issued JA1012, A Guide to the RCM Standard (2002), which amplified and clarified key concepts and terms from SAE JA1011 (p. 1). SAE JA1011 and SAE JA1012 serve as industry standards in RCM that have shaped DOD RCM policy.

- $\quad$ DOD Instruction 4151.22, Condition Based Maintenance Plus $\left(\mathrm{CBM}^{+}\right)$for Materiel Maintenance (OUSD[AT\&L], 2007), establishes policy and guidance for the Military Departments and Defense Agencies for implementation of $\mathrm{CBM}^{+}$as an essential readiness enabler used in conjunction with RCM analysis (p. 1).

- $\quad$ The HQMC issued MCO 4000.57A, Marine Corps Total Life Cycle Management (TLCM) of Ground Weapon Systems, Equipment and Materiel (2009), to incorporate RCM and $\mathrm{CBM}^{+}$into sustainment strategies (p. 12).

- $\quad$ DOD MIL-STD-3034, Reliability Centered Maintenance Process (2010), describes the methodology standard used for the determination of maintenance requirements (p. 1). 
- $\quad$ OUSD[AT\&L] released DOD Manual 4151.22-M, Reliability Centered Maintenance (2012b), which implements DOD Instruction 4151.22 and provides guidance for the RCM process to achieve reliability, restore reliability, and maintain performance characteristics for DOD materiel (p. $1)$.

\section{DOD POLICY AND RELIABILITY-CENTERED MAINTENANCE}

DOD Instruction 4151.22, Condition Based Maintenance Plus (CBM+) for Materiel Maintenance (OUSD[AT\&L], 2012a), and DOD Manual 4151.22-M, Reliability Centered Maintenance (OUSD[AT\&L], 2012b), require RCM to be used as a logical decision process to ensure effective maintenance strategies are implemented. As stated in DOD Manual 4151.22-M, "RCM provides the evidence of need for other CBM+ processes and technologies, such as health monitoring or prognostics" (OUSD[AT\&L], 2012b, p. 7). DOD Instruction 4151.22 defines CBM+ as follows:

$\mathrm{CBM}+$ is the application and integration of appropriate processes, technologies, and knowledge-based capabilities to achieve the target availability, reliability, and operation and support costs of DOD systems and components across their life cycle. At its core, $\mathrm{CBM}+$ is maintenance performed based on evidence of need, integrating RCM analysis with those enabling processes, technologies, and capabilities that enhance the readiness and maintenance effectiveness of DOD systems and components. $\mathrm{CBM}+$ uses a systems engineering approach to collect data, enable analysis, and support the decision-making processes for system acquisition, modernization, sustainment, and operations. (OUSD[AT\&L], 2012a, p. 9).

\section{J. RELATED STUDIES}

Given the current economic and political environment, leaders in the DOD will have to rely on cost-effective strategies to sustain weapon system programs. RCM and $\mathrm{CBM}+$ support that decision-making process by implementing maintenance activities or strategies that both are cost effective and increase reliability. Many people intuitively believe that the age of a physical asset, such as a vehicle, contributes to failure and increased maintenance cost to sustain reliability. This belief that equipment age contributes to failure is also present in the military with military personnel's concerns with how leaders will sustain vehicle fleets in a contracting fiscal budgetary environment (Dunn, 2013). 
A few studies in the past sought to quantify the effect of age on failure rates or $\mathrm{A}_{\mathrm{o}}$. The RAND Corporation released a study in 2004, The Effects of Equipment Age on Mission Critical Failure Rates: A Study of M1 Tanks (Peltz, Colabella, Williams, \& Boren, 2004), providing statistical analysis of the relationship between age and equipment failures. The Office of the Assistant Secretary of the Army for Acquisition, Logistics, and Technology (OASA[AL\&T]) sponsored this study to assist in the determination of recapitalization requirements to maintain a desired level of operational readiness (Peltz et al., 2004).

Peltz et al. (2004) claimed that the "age of M1 tanks is a significant predictor of non-mission capable failures, as are location and usage, and age is positively correlated with M1 failure rates" (p. xvii). The results from the study support their primary hypothesis that "M1 age has a positive log-linear effect portraying a $5 \pm 2$ percent increase in failures per year of age. Thus, a 14 year-old tank will have double the expected failures of a new tank" (Peltz et al., 2004, p. xv). Additionally, "once tank age reaches a certain point, the maintenance system may no longer be able to supply a satisfactory level of operational readiness" (p. xviii). Their claim is based on the reasoning that organizations such as Fort Riley units, with the oldest tanks in the Army's inventory, are the only active units that consistently struggle to meet the Army's operational readiness (OR) rate goal for tanks (Peltz et al., 2004). Based on monthly readiness reports extracted from the Logistics Information Database from 1999 to 2001, Fort Riley M1A1 OR averaged 88\%, while the active force M1A1 averaged 91\% (Peltz et al., 2004). Peltz et al.'s (2004) research also concluded that

while deployed to the Army's National Training Center (NTC), tank battalions equipped with older M1A1s achieved less than 70\% OR, which is considered the breakpoint for combat effectiveness. In contrast, tank battalions with the newer M1A2 averaged 83\% OR while operating at [National Training Center] NTC. (p. 6)

The M1A1 MBT fleet in the USMC is expected to remain a critical combat support platform until 2035 or beyond. The results of the RAND study support the idea that a rebuild strategy associated with the M1A1 MBT can improve readiness. It is possible that the USMC may have to increase the time between rebuilds of the M1A1 
fleet. As a result, concerns of age-related failures and their effects on reliability and readiness are surfacing. Our analysis of the USMC M1A1 fleet is similar to that of the RAND study on M1A1 and M1A2 within the Army. Our findings are comparable to results from the RAND study in our analysis of the USMC M1A1 fleet. The purpose of our research is to quantify the age-related effects on $A_{o}$ to better inform the decisionmaking process of USMC leadership in determining materiel maintenance strategies.

\section{K. M1A1 MbT REbUILd PlanNing, PROgRAMMing, BUdGeting, AND EXECUTION}

The USMC utilizes an enterprise level maintenance program (ELMP) to integrate and synchronize all stakeholders regarding depot-level maintenance for all ground weapons system and related materiel. The guidance from the commandant of the USMC is that

ELMP specifically addresses the Marine Corps' readiness and budgetary challenges by providing more precise, definitive and defensible depot maintenance requirements and budgets, improved repair efficiencies and sustained readiness for essential weapon system assets supporting critical missions. (USMC, 2012)

The USMC uses this program to ensure that its limited resources, mainly funding, are used to optimize the depot-level maintenance for Corps-wide ground equipment readiness. The M1A1 MBT rebuild process falls under the ELMP umbrella for planning, programing, budgeting, and execution (PPBE). Marine Corps Systems Command (MARCORSYSCOM), specifically, the PM Tank Systems office, is integral in developing the long-term M1A1 MBT equipment condition plan and ensuring the depot level maintenance requirements are incorporated in the ELMP according to the USMC (2012). PM Tank Systems ensures operational requirements are met by developing a M1A1 MBT rebuild strategy to maintain the requisite equipment $A_{o}$. The budget for M1A1 MBT rebuilds is determined and allocated from the ELMP funds and at \$1.5 million per rebuild for FY 2014, the M1A1 is a significantly expensive ground-based weapon rebuild program in the USMC (TACOM, 2013). Because of the funding for depot-level rebuilds being appropriated from ELMP funds, there are no costs to the 
operational unit, freeing their operational maintenance budgets for day-to-day operational needs.

\section{ANNISTON ARMY DEPOT}

The ANAD, located in Anniston, AL, is the DOD center of industrial and technical excellence (CITE) for combat-tracked vehicles such as the M1A1 MBT. As the CITE for combat-tracked vehicles, Anniston performs

depot-level maintenance on vehicles ranging in size from the Stryker to the 70 ton M1 Abrams Tank and a variety of other types in between, like the M113 Family of Vehicles, the M88 Recovery Vehicle, and the M9 Armored Combat Engineering vehicle. (ANAD, 2013b)

The Army has used the ANAD for the production, maintenance, and overhaul of M1 series family of vehicles since the late 1980s. The ANAD has been a DOD pioneer in creating and using public-private partnerships with commercial defense industry leaders such as General Dynamics, Honeywell, and BAE (Army Materiel Command [AMC], 2006). According to $\S 2474$, Title 10 U.S.C., depots can enter into public-private partnership arrangements related to their respective core maintenance competencies to improve efficiency and effectiveness of operations and support, and enhance readiness by reducing equipment repair times.

The ANAD is critical to the USMC sustainment efforts of the M1A1 MBT because of its extensive technical expertise and production capabilities. A proportion, typically $10 \%$, of the USMC M1A1 fleet, is rebuilt every year at the ANAD within the Nichols Industrial Complex. The ANAD industrial complex is International Standards Organization (ISO) 9001:2008 certified and has received the prestigious Shingo bronze award in 2007 for operational excellence in its rebuild process of the M1A1 Advanced Gas Turbine (AGT) 1500 horse power engine (ANAD, 2013a). Based on current workload and production schedules, the ANAD is able to rebuild a USMC M1A1 MBT in 63 working days comprising 5,181 direct labor hours at an average unit cost of $\$ 1.5$ million, according to the cost estimate associated with the FY 2013 M1A1 Rebuild Statement of Work. 


\section{M1A1 MBT REBUILD STRATEGY}

Over the last decade of high operational tempo associated with the wars in Iraq and Afghanistan, the USMC has adjusted its M1A1 MBT rebuild strategy to meet its operational needs. In the mid-2000s, this resulted in over 70 M1A1 MBTs rebuilt annually. At the end of the decade, as the wars began drawing down and new fiscal constraints began to impact the USMC, the rebuild strategy also changed. Based on recommendations and guidance from the PM Tank System office, the M1A1 MBT rebuild strategy transitioned to a complete overhaul of all M1A1 MBTs in the USMC fleet over 10 years (MARCORSYSCOM [PM Tank Systems], 2013). Given the current allowable strength of 399 tanks, 40 tanks per year are scheduled for rebuild at the ANAD prior to return to the fleet. Tanks that are deployed in support of Operation Enduring Freedom are not included in this number and are funded for rebuild with supplemental Overseas Contingency Operation funding.

\section{N. STATEMENT OF WORK FOR M1A1 REBUILD}

The ANAD is required to provide material, labor, facilities, missing parts, and repair parts necessary to rebuild, diagnose, restore, and test the M1A1 MBT to fulfill its requirements of the statement of work (SOW). For the remainder of this study, rebuild is defined as follows:

Maintenance technique to restore an item to a standard as near as possible to original or new condition in appearance, performance, and life expectancy ... accomplished through a maintenance technique or complete disassembly of elements using original manufacturing tolerances and/or specifications and subsequent reassembly of the items. (MARCORSYSCOM [PM Tank Systems], 2012, p. 1)

According to the SOW, dated September 4, 2012, the ANAD is responsible for restoring each M1A1 MBT inducted into the rebuild program to Condition Code "A", regardless of the condition in which the M1A1 was received. 2 The M1A1 is considered a "new" zero-

\footnotetext{
2 Condition Code "A" is defined as "serviceable/issuable without qualification, new, used, repaired, or reconditioned material which is serviceable and issuable to all customers without limitation or restriction, including materiel with more than six months shelf-life remaining" (MARCORSYSCOM [PM Tank Systems], 2012).
} 
mile / zero-hour tank after rebuild activities are complete and a Condition Code " $\mathrm{A}$ " is issued.

The M1A1 MBT rebuild process is separated into four phases: (1) pre-induction inspections; (2) rebuild; (3) inspection, testing, and final acceptance; and (4) packaging, handling, storage, and transportation (PHS\&T). Pre-induction inspection analysis is performed for each M1A1 MBT (within two weeks of receipt by depot) to identify any missing and unserviceable components. If any non-expendable component or part is missing, the ANAD reports the discrepancy back to the relinquishing command. The relinquishing command is then responsible for correcting the discrepancy before the M1A1 enters the rebuild phase. However, if the ANAD is able to correct the discrepancy with on-hand material, the ANAD updates its cost estimate and the relinquishing command is responsible for the additional cost (MARCORSYSCOM [PM Tank Systems], 2012).

The rebuild phase consists of 18 steps occurring in nine different buildings within the industrial complex. The first step of the rebuild process is to remove the turret and engine power plant from the hull. Once removed, the turret and engine power plant is transferred to additional buildings within the complex for further disassembly. Once each major section of the tank is completely disassembled, all component, assemblies, and sub-assemblies are inspected, repaired, refurbished, or replaced. If new parts are needed, based on inspections after disassembly, parts are retrieved from the ANAD supply point through an automated part retrieval system. Upon completion of the rebuild process for each section of the tank, the turret and engine are married with the hull and the tank system is inspected, tested, and painted in preparation for final acceptance.

Final inspection, testing, and acceptance occur in phase three of the rebuild process. The ANAD is responsible for planning and preparing final inspections and testing, but execution is conducted jointly with USMC personnel from MCLB Albany and Blount Island Command. Appendix B of the SOW outlines the approved limited technical inspection checklist used during joint inspections and acceptance. Any deficiencies identified in final inspections are resolved prior to preparing vehicles for 
shipment. The ANAD is responsible for arranging transportation to the required delivery site; however, the USMC is responsible for all transportation costs.

\section{O. RELEVANCE OF M1A1 REBUILD PROGRAM TO DOD LOGISTICS CAPABILITY}

The USMC M1A1 rebuild strategy is significant to the ANAD and the DOD in sustaining a core level of competence and logistics capability. Section 2464 of Title 10 U.S.C. provides, in part, that

it is essential for the national defense that the DOD maintain a government-owned, government-operated logistics capability to ensure a ready and controlled source of technical competence and resources necessary to ensure effective and timely response to a mobilization, national defense contingency, and other emergency requirements. (2013, $\S$ 2464, p. 1537)

According to ANAD officials, the depot requires an annual workload of 1.6 million hours to sustain the highest level of core competency with the M1A1 weapon system. Without the consistent demand to rebuild, on average, 40 UMSC M1A1 MBTs per year, the DOD would have to rely more heavily on foreign military sales agreements with Saudi Arabia, Egypt, and Iraq to sustain the organic M1 industrial base. 


\section{RESEARCH METHODOLOGY}

\section{A. INTRODUCTION}

In this chapter, we outline the methods by which we conducted our research. These methods include the database systems and means used in our data collection, the data collection questions we asked, and the actual processes used to analyze and interpret the USMC M1A1 MBT operational data.

\section{B. METHODS USED IN DATA COLLECTION}

\section{Qualitative Data}

Qualitative data required for our research describes the USMC's M1A1 MBT rebuild and employment strategy. We collected this data from DOD publications, Navy and Marine Corps publications, and documents supplied by the Office of the USMC PM Tank Systems. We also conducted onsite visits to the PM Tank Systems office and ANAD, where all USMC M1A1 rebuild operations take place.

\section{Quantitative Data}

To examine the M1A1 $A_{0}$, we used a six-year history, 2008-2013, from the USMC's System Operational Effectiveness (SOE) application to acquire data on the M1A1, specifically the annual downtime and uptime per tank by serial number. The SOE application was developed by Alion's Weapon Systems Technology Information Analysis Center (WSTIAC) to support the readiness and supportability needs of MARCOSYSCOM according to the Capabilities Assessment Support Center (CASC; 2013). This online application uses data from numerous USMC data sources in order to compile a comprehensive repository of operational effectiveness data regarding USMC weapons systems. Data received from SOE includes all equipment repair orders (EROs), part requisitions, dead lining events, and $\mathrm{A}_{\mathrm{o}}$ for all M1A1 MBTs in the USMC. To compensate for known data integrity issues identified during the development of SOE, SOE developers made several assumptions, such as assuming no delays in data entry, and assuming serial numbers outside three to six alphanumeric characters were identified as 
erroneous and were eliminated from summary data, according to the CASC (2013). See Appendix 2 for a complete list of assumptions used in data validation in the SOE application. We also acquired an MS Excel spreadsheet maintained jointly by ANAD and the PM Tanks Systems office that tracked the tank rebuilds by serial number from 2004 to 2013.

\section{DATA COLLECTION QUESTIONS}

\section{Tank Age}

In order to determine the correlation between $A_{o}$ and age, we first needed to determine the age of the tanks in our data pool. For our research, we defined the age of a tank as the elapsed time since its last complete rebuild (LCR) at the ANAD. Only tanks, with which we could determine the age, as we've outlined here, are included in our data pool. Additionally, because the earliest record of rebuild we have is 2004, the maximum age possible in our experiment is nine years, though we excluded the nine-year-old tanks, as explained later. The age, as we have defined it, is not a representation of the age of all components because individual parts are replaced over time. It is, however, an analysis tool used to measure time since rebuild for the purposes of our project. This created a baseline due to the fact that every tank that leaves Anniston after rebuild is in the same condition and considered a zero-age, zero-miles tank, regardless of the condition it was in prior to the rebuild. We did not include tanks overhauled under an "inspect and repair only as necessary" (IROAN) program or other contract. Additionally, we exempted all zero-year tanks in our analysis because of the reduced operational time available that year, resulting in an age range of one to eight years of age for the tanks used in this research.

\section{Applicable USMC Regions}

The SOE application classifies each piece of equipment as belonging to a specific region, as defined by Table 1 . 
Table 1. USMC Region Codes

\begin{tabular}{|c|c|}
\hline Region & Description \\
\hline MIM001 & I MEF, Camp Pendleton, CA \\
\hline MIM002 & II MEF, Camp Lejeune, NC \\
\hline MIM003 & III MEF Okinawa, JP \\
\hline MIM004 & IV MEF Reserves \\
\hline MIM007 & VII MEF Deployed Units \\
\hline MIM008 & Bases, Posts, and Stations \\
\hline MIMMPS & Maritime Prepositioned Fleet \\
\hline
\end{tabular}

For our project, we limited our data pool to MIM001, MIM002, and MIM004 in order to standardize the type of unit examined. These three regions contain the major tank battalions in the USMC. Because a large amount of the USMC MBT fleet is encompassed in the MIMMPS region, we did not include it because of the lack of usage when assigned to the MPS. While on these ships, the tanks have very minimal usage, if any. We did not include the other regions because of lack of tanks assigned (MIM003), unusual operational tempo (MIM007), and minimal tanks assigned and special usage (MIM008).

\section{Operational Availability}

The primary goal for this research project was to determine the correlation between age and operational availability $\left(\mathrm{A}_{\mathrm{o}}\right)$ of the USMC M1A1 MBTs. The SOE application calculated the $A_{o}$ of each tank using uptime and downtime due to dead lining events. With this data, we were able to calculate the average $A_{o}$ by tank age through each of the six years of SOE data. By using the average $\mathrm{A}_{\mathrm{o}}$ by age, we created a weighted average that would compensate for having less data on older tanks when using regression to determine the correlation between age and $\mathrm{A}_{\mathrm{o}}$.

\section{Exclusion of Observations}

While reviewing the data collected for analysis, we determined that some observations would have to be excluded from the pool in order to ensure data quality. Tanks that were listed as down due to dead lining conditions for greater than half a year, 
182 days, were assumed to be used to provide parts to other tanks (i.e., cannibalized). They therefore wouldn't provide an accurate depiction of availability.

In 2011, the USMC had 58 tanks overhauled at the ANAD using a separate contract following an IROAN program. Because this doesn't qualify as a complete rebuild and significantly differentiates these tanks from the standard rebuilds, those 58

tanks were excluded from our data pool beginning in 2011 but were counted prior, if applicable.

We also noticed that the SOE database sometimes had multiple entries for a given serial number and year. Duplicated entries were removed, while those with different information were eliminated using the following standards. The first discriminator was downtime, the entry with the higher amount of downtime remained, while all subsequent entries were excluded. If these values were the same for multiple entries, then the deadline EROs value was used to eliminate extra entries to ensure that each tank serial number was used only once per year in our data pool.

Finally, we excluded the tanks that were nine years old for two main reasons. The first reason is that the number of occurrences of this age group is only .5\% of the total sample pool. Commanders at the unit level decided which tanks were sent to rebuild, and the assumption is they would most likely send problematic tanks, not operational ones. Because of these two factors, we assumed that these tanks did not accurately represent the population of M1A1s in the fleet. At the conclusion of all data exclusions, we narrowed 2,023 entries to 891 for use in our data pool.

\section{ANALYTICAL PROCESS}

In our analysis for this project, we used a simple linear regression model in order to determine a correlation between the dependent variable, $\mathrm{A}_{\mathrm{o}}$, and the explanatory variable, age. This allowed us to determine the true significance of tank age as previously defined in relation to M1A1 availability to the USMC fleet.

We also conducted a what-if analysis for the number of tanks the USMC sends to the ANAD for rebuild each year. We forecasted the average age of the USMC M1A1 
fleet through 2035 given current and potential reduced rebuild levels to predict the average $A_{o}$ in the fleet.

\section{E. SUMMARY}

In the first three chapters, we discussed the current USMC M1A1 MBT rebuild process, the force structure breakdown and flow of the USMC fleet, and the data used to conduct our project. This laid a foundation of understanding of our research question and analysis. In the final two chapters, we outline the analysis of our gathered data in order to answer our primary research question and provide valuable information to the PM Tank Systems office and other USMC decision-makers regarding the MBT rebuild strategy. Additionally, we provide areas for future research. 
THIS PAGE INTENTIONALLY LEFT BLANK 


\section{RESULTS AND ANALYSIS}

\section{A. INTRODUCTION}

In this chapter, we discuss the results of the analysis conducted during this project. We focused on the correlation between operational availability $\left(A_{o}\right)$ associated with dead lining criterion for the M1A1 MBT and elapsed time since last rebuild using historical operational data from the USMC. We used a simple regression analysis to determine this correlation while also identifying its coefficient of determination. Using this correlation, we conducted a what-if analysis to determine average $\mathrm{A}_{\mathrm{o}}$ given various numbers of tanks rebuilt each year. We combined the correlation between age and $A_{o}$ with the forecasted age of the USMC M1A1 fleet at current and potential reduced rebuild levels.

\section{B. M1A1 OPERATIONAL AVAILABILITY BY AGE}

\section{Overview}

The USMC M1A1 fleet rebuild program transfers tanks from the operational fleet to the ANAD and, regardless of age and condition, rebuilds them to what is considered a zero-miles, zero-years tank. A common indicator used in evaluating the status of a fleet of equipment is age. This metric is easily obtained and an accurate indicator of $\mathrm{A}_{\mathrm{o}}$; therefore, it can be a powerful tool for strategic decision-makers. The purpose of this section is to define the correlation between age and $\mathrm{A}_{\mathrm{o}}$ for the USMC M1A1 fleet.

\section{Data Collection}

We collected operational data on the USMC M1A1 MBT using the SOE database over a six-year period, 2008-2013. This data included the uptime and downtime for each tank in relation to dead lining events and the year in which they occurred. Additionally, we received M1A1 rebuild information from the Tank Systems program office. At the conclusion of the data exclusion, we had a final sample of 891 USMC M1A1 annual data points. 


\section{Age of Tanks}

For this project, some tanks are counted up to six times, once for each year 20082013 from the SOE database. In each case, as the year advances, the tank's age also advances; so multiple uses of tanks occur. The formula to determine the age in relation to last rebuild is

$$
\text { Age }=\text { Year }- \text { LCR }
$$

Year: the year of data measured is SOE

LCR: year of last complete rebuild

Through applying this formula, our sample resulted in the below distribution, with regional breakdown, of tank ages. The average age of the tanks in our sample of 891 occurrences was 3.26 years since last rebuild, see Figure 3.

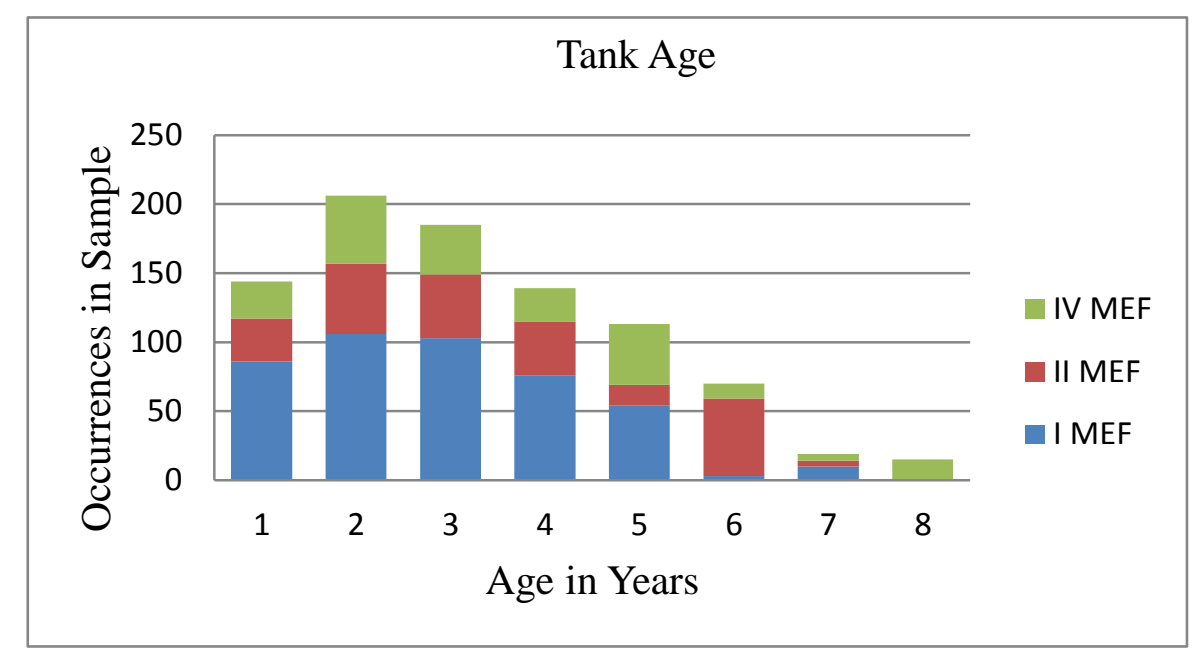

Figure 3. M1A1 Data Pool Age Histogram

\section{Operational Availability}

The SOE database compiled and calculated the $\mathrm{A}_{\mathrm{o}}$ of each tank using Equation 3.

$$
A_{O}=\frac{\text { Up Time }}{\text { Up Time }+ \text { Down Time }}
$$

The SOE had three different uptimes and downtimes for each tank: overall, critical, and deadline. For this project, we used only the times associated with dead-lining events. 
We did not use the other uptimes and downtimes because these data points include supply requisitions in their calculations, not just mission capability. We then examined this $A_{o}$ to determine whether a correlation with age existed.

\section{Age and Operational Availability Correlation}

For our project, we combined the average $A_{o}$ for each age of tanks, one to eight years. These averages are displayed in Table 2.

\section{Table 2. Compiled Tank Data}

\begin{tabular}{|c|c|c|c|c|c|c|c|c|}
\hline \multirow{2}{*}{ Age } & \multirow{2}{*}{ Tanks } & \multicolumn{3}{|c|}{ Regions } & \multirow{2}{*}{ ERO (Deadline) } & \multirow{2}{*}{ Uptime(Deadline) } & \multirow{2}{*}{ Downtime (Deadline) } & \multirow{2}{*}{ Ao (Deadline) } \\
\hline & & I MEF & II MEF & IV MEF & & & & \\
\hline 1 & 144 & 86 & 31 & 27 & 100 & 45512 & 2448 & 0.948957465 \\
\hline 2 & 206 & 106 & 51 & 49 & 173 & 66531 & 3748 & 0.946669702 \\
\hline 3 & 185 & 103 & 46 & 36 & 222 & 59987 & 5481 & 0.916279709 \\
\hline 4 & 139 & 76 & 39 & 24 & 171 & 43146 & 5587 & 0.885354893 \\
\hline 5 & 113 & 54 & 15 & 44 & 127 & 31456 & 4105 & 0.884564551 \\
\hline 6 & 70 & 3 & 56 & 11 & 55 & 16493 & 1370 & 0.923305156 \\
\hline 7 & 19 & 10 & 4 & 5 & 14 & 4264 & 715 & 0.856396867 \\
\hline 8 & 15 & 1 & 0 & 14 & 27 & 4052 & 743 & \begin{tabular}{|l|}
0.845046924 \\
\end{tabular} \\
\hline Totals & 891 & 439 & 242 & 210 & & & & \\
\hline
\end{tabular}

To find the correlation between the age of the tanks and the $A_{o}$, we used a simple linear regression tool in MS Excel 2010. Our regression yielded a coefficient of determination, or R-squared, value of .743. We used $A_{o}$ as the dependent variable and age as the explanatory variable, using the data from Table 2, resulting in a negative correlation between age and $\mathrm{A}_{\mathrm{o}}$ (see Figure 4). 


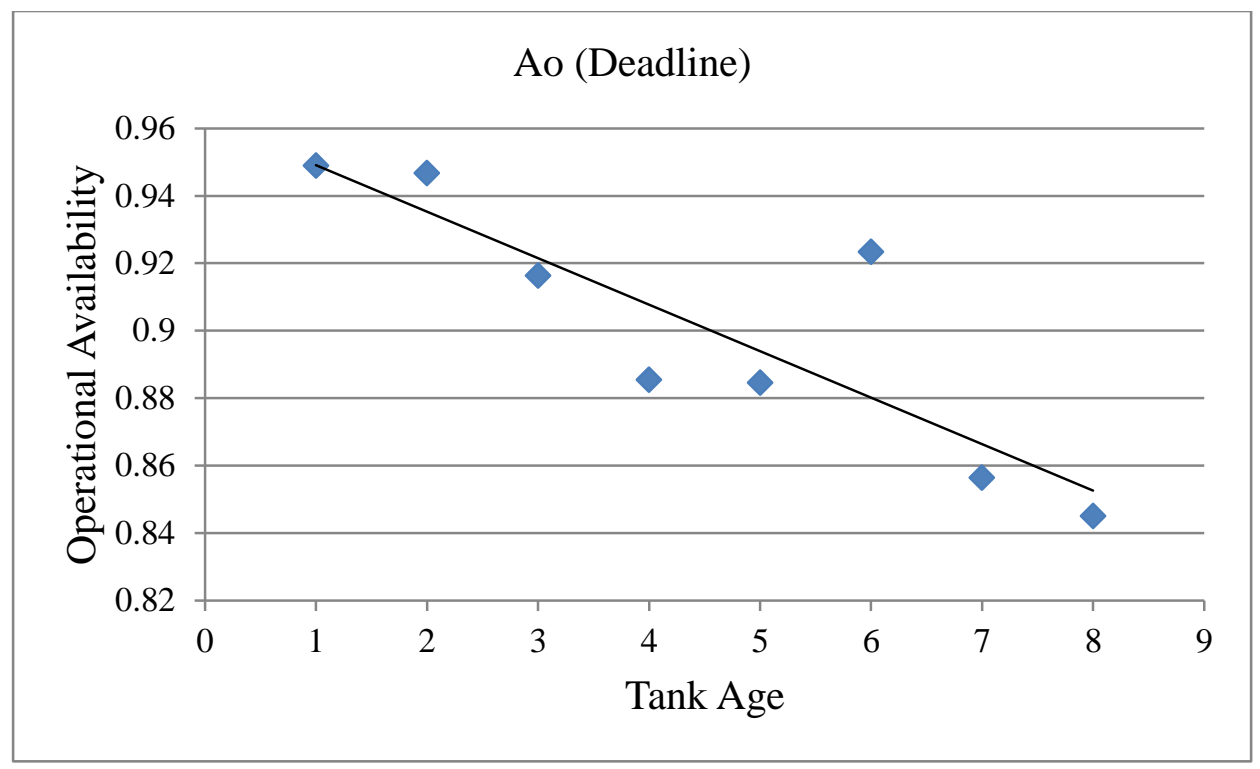

Figure 4. Operational Availability by Age

Based on this simple linear regression, the equation to determine the $\mathrm{A}_{\mathrm{o}}$ of a tank given the time since its last complete rebuild is

$$
\mathrm{A}_{\mathrm{O}}=-0.0138 \times \text { Age }+.9629
$$

Given our assumptions, this equation predicts that each tank will decrease in $\mathrm{A}_{\mathrm{o}}$ by .0138 each year it gets older.

\section{Analysis}

Our regression model is a valuable tool that can be used to determine the link between age and $\mathrm{A}_{\mathrm{o}}$ for the USMC M1A1 MBT fleet. Our R-squared value of .743 indicates there is a fairly strong correlation between the age of the tanks and their operational availability. This correlation does not mean age is the cause of the degradation in availability, rather, it is an indicator used to forecast availability. Our results, when compared to a similar report done by the RAND Corporation, share some similarities. Although the RAND study (Peltz et al., 2004, p. xv) included factors other than age, used a negative binomial regression, and looked at the number of mean failures as opposed to $A_{0}$, both studies show a negative correlation between age and operational availability. In our study, the percent decrease of $A_{o}$ from year to year is $1.4 \%$, while the 
RAND study showed mean failures, which contribute to a reduction in $\mathrm{A}_{\mathrm{o}}$, grew at a rate of $5 \pm 2 \%$ compounded annually (Peltz et al., 2004, p. xv). The RAND study also used Army tanks, which conduct depot-level maintenance at the ANAD but do not conduct complete rebuilds like the USMC, and thus, used manufacture date to determine age.

\section{WHAT-IF ANALYSIS}

\section{Overview}

Over the past decade, the USMC has fluctuated in the annual quantity of tanks rebuilt, surging when necessary, to over 70 tanks in a single year. Currently, the USMC is using $10 \%$ of the AAO, or 40 tanks per year as the rebuild level. As combat operations and funding decrease, rebuild quantities are highly scrutinized to ensure proper use of limited resources. Given the correlation between age and $\mathrm{A}_{0}$, the purpose of this section is to compare fleet strength over time given different annual rebuild quantities.

\section{Data Collection}

We started with 450 tanks tracked by the USMC in 2013, including Marine Expeditionary Force (MEF), MPS, DFMA, and non-MEF assignments. We also used the rebuild spreadsheet used by the ANAD and the PM Tank Systems office to determine the most recent rebuild for each of the 450 tanks to forecast the average age of the fleet over time given different rebuild levels. Although we excluded the tanks that were part of the IROAN contract in 2011 for the correlation calculations, we classified them as rebuilt that year for the purposes of this section's forecasting.

\section{Average Age Forecast}

In order to calculate the average age over time given the different rebuild levels, we first defined the current age of the USMC fleet. Using Equation 2 from the previous section, we measured the elapsed time in years since each tank's last complete rebuild or IROAN maintenance. See Figure 5. 


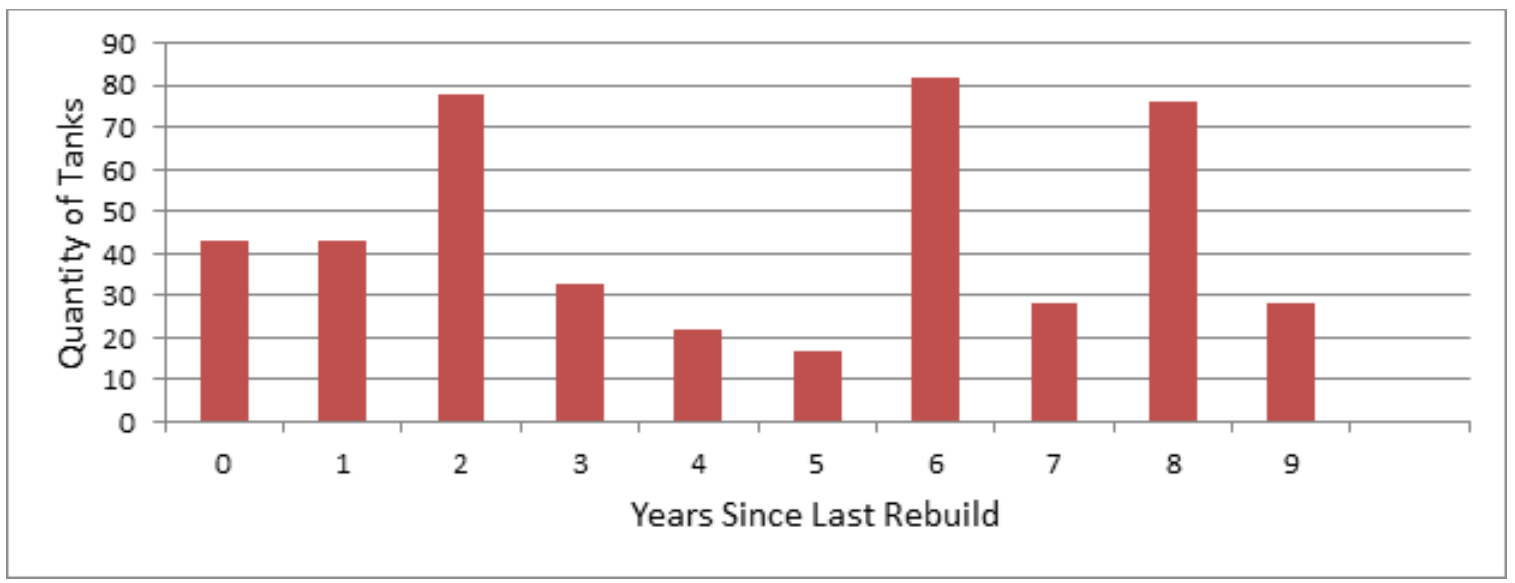

Figure 5. Quantity of Tanks by Age in 2013

In 2013, the average age of the fleet was 4.49 years, with the oldest tank being nine years since its last rebuild.

In order to forecast the average age of the USMC M1A1 fleet, given the 2013 levels, we applied one assumption about how the tanks would be selected for rebuild. We assumed that each year, the oldest tanks were selected for rebuild, regardless of rebuild level. For example, if 40 tanks are sent to ANAD for rebuild each year, then each year the 40 oldest tanks in the USMC fleet were selected. In reality, tanks are selected by operational commanders using their own criteria combined with guidance from MARCORSYSCOM and M1A1 depot-level evacuation criteria annotated in TI-08953A14/9. We used rebuild levels from 30 to 40 tanks per year and forecasted out to the year 2035, the expected life of the USMC M1A1. Given this constant process for rebuild, each level of rebuild reached an equilibrium state where the average age of the tanks remains constant. These equilibriums occurred between 2023 at 40 tanks per year, and 2027 with 30 tanks per year, as depicted in Figure 6. 


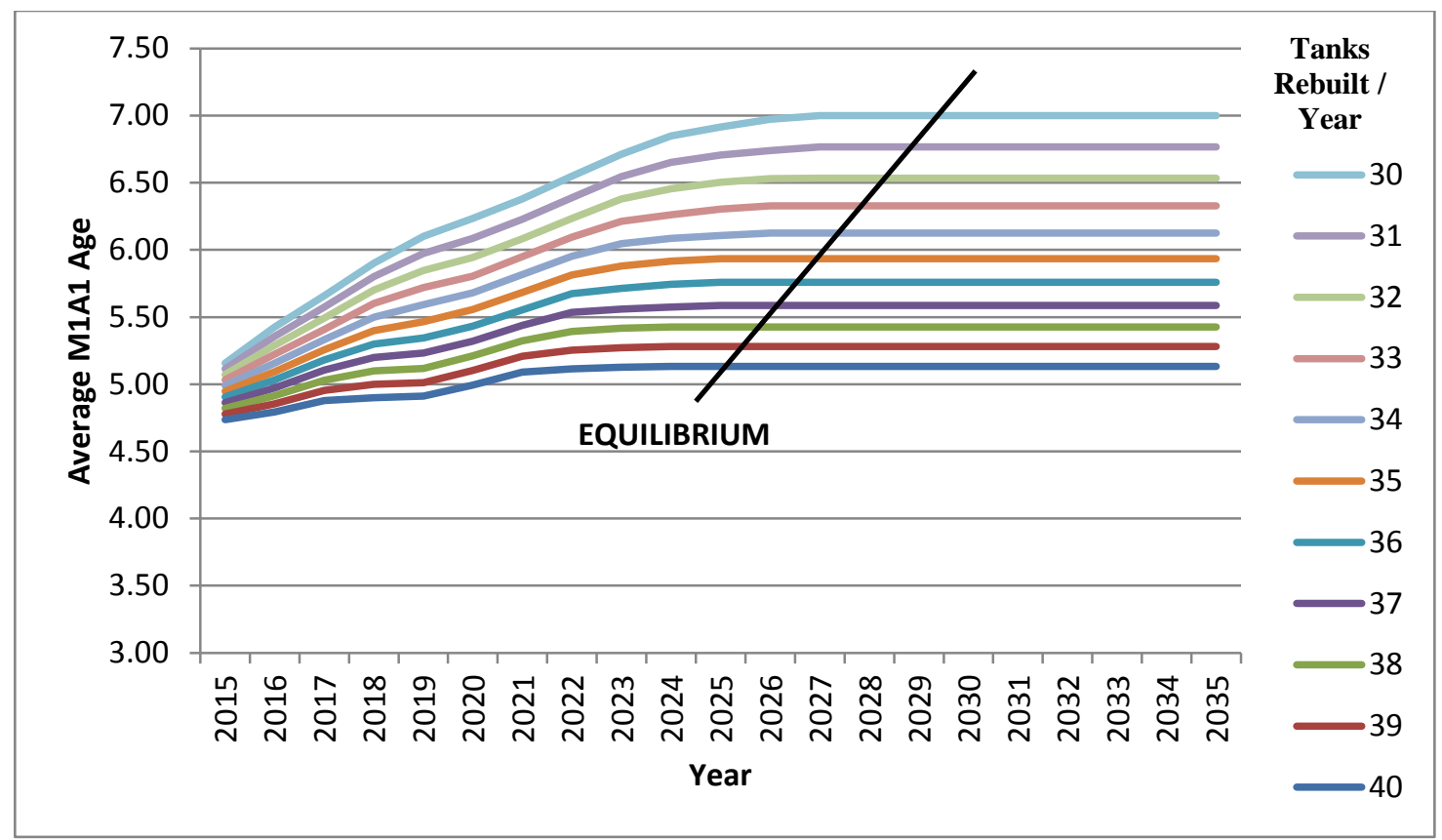

Figure 6. USMC M1A1 Forecasted Age Through 2035 by Rebuild Level

Given the different rebuild levels of 30 and 40 tanks per year, over time, the maximum difference in the average age of tanks in the USMC fleet was 1.87 years and occurred in 2027.

\section{Combat Power Comparison}

Given the forecasted average age of the USMC M1A1 fleet and a linear relationship between age and $A_{o}$, we were able to calculate the average $A_{o}$ of the USMC tank fleet through 2035. We applied Equation 3, determined during our linear regression, to the average annual ages of tanks in order to determine the annual $A_{o}$ per year by rebuild level, as depicted in Figure 7. 


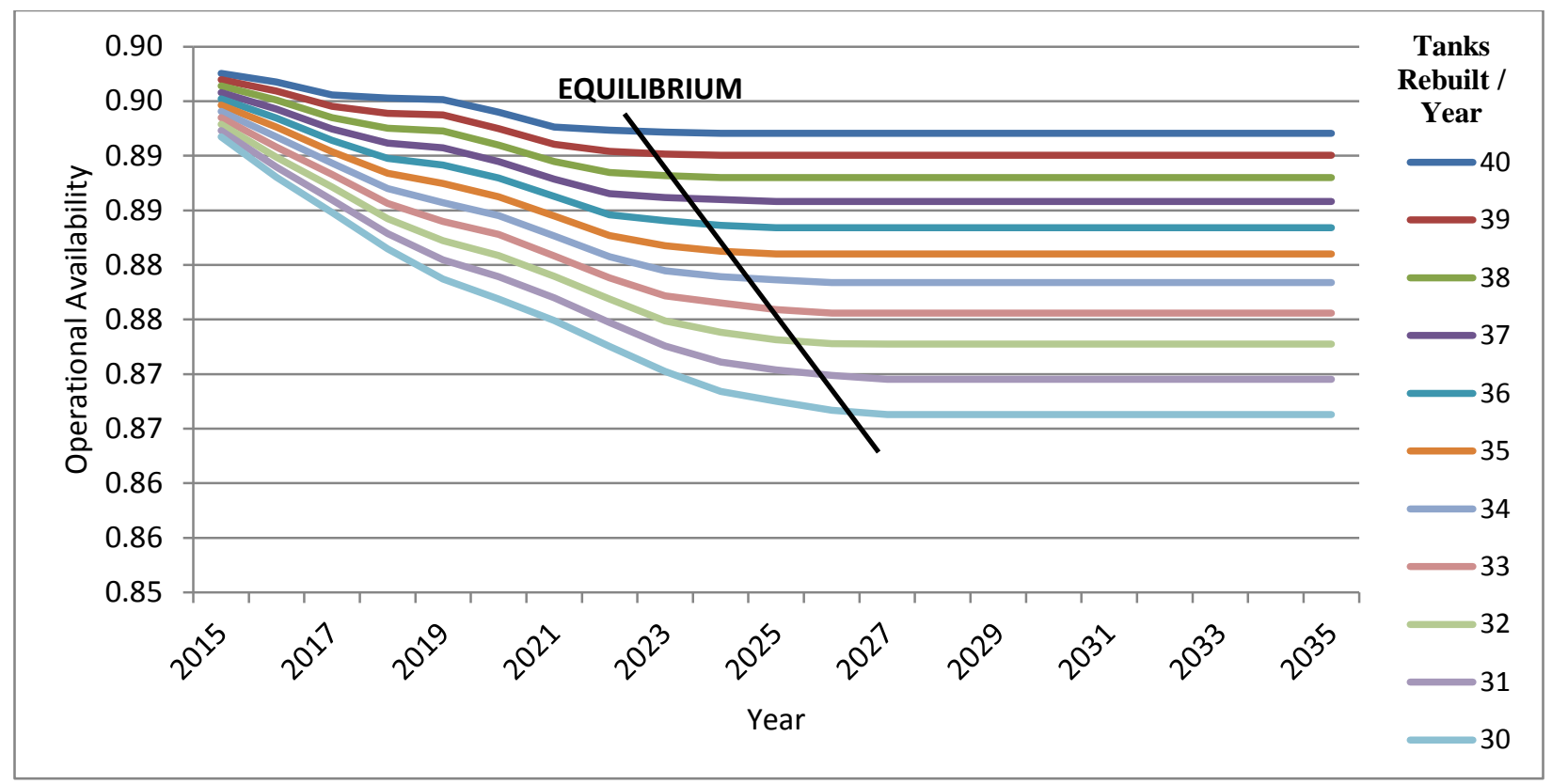

Figure 7. USMC M1A1 Forecasted $A_{o}$ Through 2035 by Rebuild Level

Since the age of the tanks reached an equilibrium and the $A_{o}$ shares a linear relationship with age, the $A_{o}$ also reached equilibrium. At these rebuild levels, the most significant difference between $\mathrm{A}_{\mathrm{o}}$, again in 2027 between 40 tanks per year and 30 tanks per year, was.0258 in 2027. Using Equation 5, the net difference in average FMC tanks based on $\mathrm{A}_{\mathrm{o}}$ between these two rebuild levels is 2.32 FMC M1A1s in 2015 and 10.28 FMC M1A1s in 2027 at an AAO of 399 tanks. Conversely, increasing the number of tanks rebuilt per year by 10 could increase fleetwide FMC by almost eight tanks. USMC decision-makers can use this relationship when determining depot support to optimize USMC capability given fiscal constraints.

FMC Tanks $=\mathrm{A}_{\mathrm{o}} \mathrm{x}$ AAO 


\section{MODEL LIMITATIONS}

Our analysis assumes a linear relationship between the dependent variable $\left(\mathrm{A}_{\mathrm{o}}\right)$ and the independent variable (age). The range of the independent variable within our observations was from one to eight years of age. Our regression model can explain approximately $74 \%$ of the variation in $A_{o}$ based on age as the independent variable. If our model were to be used to predict $A_{o}$ based on M1A1 MBT age greater than eight years, the predicted results becomes increasingly inaccurate as age increases beyond eight years. Additionally, our model considers tank age only to predict $A_{o}$ and omits usage effects.

Our study defines the age of a tank as the elapsed time between last complete rebuild at the ANAD. In order to estimate the future average age of the M1A1 fleet, at various rebuild intervals, we assumed that the USMC would select the oldest tanks available for rebuild. Generally, tanks should be considered a candidate for rebuild when operational usage exceed 30 months, 300 hours, 750 rounds fired, or 3000 miles traveled according to USMC Inspection and Evacuation Criteria for Tank, Combat, Full Tracked, 120mm, M1A1 (USMC, 1997, p. 2). Our assumption that the oldest available tanks will be chosen for rebuild is in line with USMC evacuation criteria; however, it is known that tanks are frequently selected based on reliability issues rather than age or usage. Thus, our forecasted average age of the M1A1 fleet illustrates a best-case scenario achieving the lowest possible average age of the fleet, given that the oldest tanks are selected for rebuild. If the USMC continues to select tanks for rebuild based on reliability rather than age, the actual average age of the fleet will increase, resulting in a likely increase in standard error between forecasted and actual $\mathrm{A}_{\mathrm{o}}$ when utilizing our model.

M1A1 tanks that were reported as non-mission capable for greater than 182 days due to dead-lining conditions were assumed to be cannibalized. In this situation, cannibalization refers to removing functional parts from a non-mission capable tank to correct faults on other tank(s). In general, cannibalization is a quick, short-term solution that has been viewed as a symptom of an inadequate supply chain resulting in spare part shortages (Curtin, 2001, p. 2). According to Neal Curtin, Director, Defense Capabilities and Management, and his testimony to the Congress in 2001, as many as half of all 
cannibalizations may go unreported (p. 4). Unreported cannibalization may result in the "masking" of dead-lining events of other equipment, resulting in failures to be understated in SOE. These unreported failures directly reduce the accuracy of our model, resulting in our forecasted $\mathrm{A}_{\mathrm{o}}$ to be overstated. The frequency of cannibalizations at the operational level was not included in our study, and the number of cannibalization occurrences and reason for cannibalization is considered to be unknown.

\section{E. SUMMARY}

In this chapter, we used the data collected from the USMC to analyze the correlation between the elapsed time since last M1A1 rebuild and $\mathrm{A}_{0}$. We determined the current age of the USMC M1A1 fleet and forecasted the age out 20 years given various rebuild levels. Finally, we combined the correlation and the forecasted age to determine the effect on combat power of reducing the number of tanks rebuilt annually. In the next section, we make recommendations of information for decision-makers to consider when determining the appropriate level of M1A1 rebuilds per year. 


\section{RECOMMENDATIONS}

\section{A. APPLICATION OF MODEL}

\section{Depot-Maintenance Planning}

Our model is a tool that forecasts the effects of a change in age of USMC tanks and does not generate an optimal rebuild level for USMC M1A1s. The linear model generated in our research can, however, aid USMC senior leadership in determining the required quantity of M1A1 tanks rebuilt each year to achieve a desired $A_{0}$. At the strategic level, leaders will determine the required combat power of the M1A1 and use our average age forecast at various rebuild levels and linear equation, relating age to $\mathrm{A}_{\mathrm{o}}$ to ensure that combat power is achieved given current M1A1 unit authorizations. Because the USMC consolidates depot-level maintenance planning using ELMP, this model can assist in trade off analysis to ensure that the USMC optimizes its use of limited resources. If rebuild levels change annually, average age forecast must be redone to accommodate the variations prior to applying the linear model relating age to $\mathrm{A}_{\mathrm{o}}$.

\section{Tank-Deployment Selection}

The linear model linking the age of an USMC M1A1 tank to its $A_{o}$ can also be used to assist military leaders in operational planning. Rather than using a fleet-wide average $\mathrm{A}_{\mathrm{o}}$ for the tanks used, leaders can apply our linear model to have a more realistic idea of the equipment availability throughout future operations. Knowing a more accurate $A_{o}$ will enable logisticians to plan and manage the logistical footprint required for the operation more efficiently, saving money and increasing availability. This knowledge will also enable commanders at all levels to ensure they have a more realistic planning estimate of the combat power available throughout the duration of an operation.

\section{B. FURTHER RESEARCH}

Our model clearly identifies a correlation between age and $A_{o}$ of the USMC M1A1 tanks. There are, however, other factors that can influence a tank's availability 
that could be explored in future research. Examining usage, environment, and time spent on MPS ships could give a more accurate availability for the fleet. Additionally, it could help optimize M1A1 distribution throughout the MEFs to ensure capabilities are uniform across the fleet.

As modifications and improvements to the M1A1 Abrams continue, failures that require maintenance and reduce $A_{o}$ should be examined to define trends. Future research could focus on dead lining failures by tank subcomponents such as engine, turret, transmission, electronics, and weapons. Identifying the most prevalent failures can optimize maintenance planning, engineering changes, and supply-chain management to improve $A_{0}$.

The current rebuild strategy replaces all parts regardless of condition. Although this assists in reducing the turnaround time for the rebuilds by cutting down inspection and process time, it may unnecessarily replace certain parts. Further research might examine different methods for rebuild and depot maintenance, such as the use of an IROAN program, and compare them to the current strategy.

Finally, further research could examine the cost transference caused by reduced annual rebuild levels. Cost savings from sending fewer tanks to ANAD each year will be offset to some degree with increased maintenance required at the organizational level. This transference, coupled with projected operational availability using our model, would give senior decision-makers more information to make strategic sustainment decisions. 


\section{APPENDIX A. USMC M1A1 MBT SPECIFICATIONS}

Appendix A illustrates a summarized list of key M1A1 MBT specifications and characteristics that were retrieved from the M1A1 operators manual (TM 9-2350264-10-1).

\begin{tabular}{|c|l|}
\hline & M1A1 MBT \\
\hline Dimensions and weights & \\
\hline Crew: & 4 \\
\hline Length & \\
\hline overall: & 387.0 in \\
\hline main gun rearward: & 355.6 in \\
\hline Width & \\
\hline overall: & 143.75 in. \pm 0.54 in \\
\hline without skirts: & 136.0 in \\
\hline Height & \\
\hline to turret roof: & 96.0 in \\
\hline Maximum overall: & 113.6 in \\
\hline Ground clearance & \\
\hline hull: & 19.0 in \\
\hline hull sides: & 17.0 in \\
\hline Weight & \\
\hline MLC: & $67(\mathrm{w} / \mathrm{T}-156$ track); 68 (w/ T-158 track $)$ \\
\hline Mobility & \\
\hline Configuration & \\
\hline running gear: & tracked \\
\hline Power-to-weight ratio: & 23.77 hp/t \\
\hline Speed & \\
\hline max speed: & $41.5 \mathrm{mph}$ \\
\hline Range & \\
\hline main fuel supply: & 264.7 miles \\
\hline Fuel capacity & \\
\hline Total in all tanks: & 504.4 US gallons \\
\hline Fording & \\
\hline without preparation kit: & 48.0 in \\
\hline with preparation kit: & Turret roof \\
\hline Gradient: & $60 \%\left(31.0^{\circ}\right)$ \\
\hline Side slope: & $40 \%\left(22.0^{\circ}\right)$ \\
\hline Turning radius: & 171.7 in \\
\hline Engine: & AGT $1500,1,500 \mathrm{hp} \mathrm{at} 30,000 \mathrm{rpm}$ \\
\hline Gearbox & \\
\hline & \\
\hline & \\
\hline
\end{tabular}




\begin{tabular}{|c|c|}
\hline model: & Allison Transmission X-1100-3B \\
\hline type: & automatic \\
\hline forward gears: & 4 \\
\hline reverse gears: & 2 \\
\hline \multicolumn{2}{|l|}{ Brakes } \\
\hline main: & Hydraulic-mechanical service brake (foot) \\
\hline Suspension: & advanced torsion bar \\
\hline \multicolumn{2}{|l|}{ Electrical system } \\
\hline vehicle: & $24 \mathrm{~V}$ \\
\hline Batteries: & $6 \times 12 \mathrm{~V}$ \\
\hline \multicolumn{2}{|l|}{ Firepower } \\
\hline Armament: & $\begin{array}{cccc}1 \times \text { turret mounted } 120 \mathrm{~mm} \mathrm{M} 256 \text { smoothbore } & \text { gun } \\
1 \times \text { coaxial mounted } 7.62 \mathrm{~mm} \mathrm{M} 240 \text { machine } & \text { gun } \\
1 \times \text { roof mounted } 12.7 \mathrm{~mm} \mathrm{M} 2 \text { HB machine } & \text { gun } \\
1 \times \text { roof mounted } 7.62 \mathrm{~mm} \mathrm{M} 240 \text { machine } & \text { gun } \\
12 \times \text { turret mounted smoke grenade launcher }(2 \times 6) & \end{array}$ \\
\hline
\end{tabular}




\section{APPENDIX B. SYSTEM OPERATIONAL EFFECTIVENESS ASSUMPTIONS}

The summary options available within the SOE Decision Support Tool are based on data records obtained from numerous USMC data sources. Several assumptions were required to summarize these data records as numerous data integrity issues were identified during the development of the SOE Decision Support Tool. The following list identifies some of the more pertinent assumptions that were derived during the development of the various summary options within the SOE Decision Support Tool.

1. All dates recorded in MIMMS and ATLASS II+ for

Date_Received_In_Shop (DRIS) of an ERO, Date_Closed associated with an ERO, Date_Ordered associated with order of parts, and

Date_Received_Cancelled associated with receipt of parts are assumed to be accurate (i.e., there is no delay in entering these dates into maintenance management systems).

2. When determining equipment repair order (ERO) metrics in which parts were ordered or received outside of the "bookends" of the ERO (i.e., DRIS and Date_Closed), the dates coinciding to the order or receipt of these parts is shifted to coincide with the ERO "bookends." But when determining the logistics response time (LRT) for these parts it is determined inconsequential of these ERO "bookends."

3. The criticality codes (CCs) from the APPS40 files are assumed to be accurate. Therefore, a CC of 5 represents a critical part and all other CCs are assumed to represent non-critical parts.

4. The critical maintenance downtime (MDT) will be determined based on the days that the equipment was in a deadlined status, which will use data from the Deadline_Control_Date (DCD), Category_M_Days_Deadlined, and critical logistics response time (LRT) fields.

5. The percentage of critical parts versus the total number of parts used within an ERO is used to calculate the critical active maintenance time (AMT) and subsequently the critical administrative delay time (ADT). Where critical AMT is equal to this percentage multiplied by total AMT for ERO. 
6. The accuracy of labor hours tracking in the Military_Labor_Hours and Manhours 1, 2, and 3 are assumed to be valid in MIMMS and ATLASS II+.

7. When converting Military_Labor_Hours or sum of Manhours 1, 2, and 3 to days for the AMT calculation it is assumed that 8 hours is equal to 1 day.

8. It is assumed in the Weapon System Criticality and Parts Criticality summary options that the four factors that are used to determine the overall criticality of the weapon systems and parts should be equally weighted (i.e., 25\% weighting per factor). Future versions of SOE Decision Support Tool may provide a capability to vary weighting factors for customizing specific program needs.

9. Since item designator number (IDN) information is not collected within the ATLASS II+ maintenance management system there is no way to summarize this data by IDN for the various equipment operated in II MEF while ATLASS II+ was being utilized (i.e., Camp Lejeune, NC). Therefore, a new IDN (ATLASS) was created to summarize these data records by IDN.

10. Serial numbers must be between 3 and 6 alphanumeric characters in length. All other serial numbers are assumed to be erroneous and are eliminated from data summarization. (Note: The SOE Decision Support Tool does not currently account for serial number "O" events in which multiple weapon systems are inducted into maintenance for a common event.)

11. EROs with the same ERO number, region, and DRIS are assumed to be duplicates and are eliminated from consideration for data summarization.

12. EROs in which the Date_Closed or DRIS (Julian date formatted as yyddd or 97001 for January 1, 1997) identify the day as 000 are assumed to be erroneous and are eliminated from consideration for data summarization.

13. Dates for Date_Closed, DRIS, Date_Ordered, and Date_Received_Cancelled must be greater than 3 digits in length (i.e., acceptable Julian date formats are yddd or yyddd only). Data records that do not comply are assumed to be erroneous and are eliminated from consideration for data summarization

14. EROs that have a Defect Code of "777" or "999" are assumed to be erroneous as these represent unsuccessful attempts to move TC-AIMS or ATLASS II+ data records into the MIMMS format. These EROs are eliminated from consideration for data summarization. 
15. If the IDN field is $\langle$ NULL $>$ for a data record the record is eliminated from consideration for data summarization.

16. The national stock number (NSN) must be 13 digits in length or the data record associated with NSN should be eliminated from consideration for data summarization.

17. The federal supply class (FSC) is the first 4 digits of the NSN. If the FSC is " 2540 " or " 4210 " then the parts are assumed to be tools which are removed from consideration for data summarization.

18. The national item identification number (NIIN) is the last 9 digits of the NSN. If the NIIN is equal to " 511000000 " or between "528100000" and "999999999" it is assumed to be a tool as well, thus eliminated from data summarization consideration.

19. An exception has been made for SL-3 items so these items will not be summarized in criticality reports. SL-3 items will remain visible though, so their costs can be reviewed by users (i.e., PMs).

20. If the Date_Received_Cancelled (date part received) occurs prior to the Date_Ordered (part order date) for a part the data record is assumed to be erroneous and removed from consideration for data summarization.

21. If the Date_Received_Cancelled is equal to "9999" (in format of yddd) it is assumed to reflect a cancelled order and therefore is removed from data summarization consideration.

22. The Region and Fleet summary options within the Maintainability Metrics section of the SOE Decision Support Tool eliminate data records in which the AMT>20 days from data summarization consideration.

23. Year selection options refer to government fiscal year (i.e., October 1st through September 30th). 
THIS PAGE INTENTIONALLY LEFT BLANK 


\section{APPENDIX C. SYSTEM OPERATIONAL EFFECTIVENESS FIELD DEFINITIONS}

Appendix C provides a brief description of column fields within the SOE database. The SOE database was the primary data source used in our analysis of operational availability. The System Operational Effectiveness (SOE) user guide (2013), version 1.0.1.3, can provide more information regarding the functions and capabilities of the SOE database.

\begin{tabular}{|c|c|}
\hline Field & Description \\
\hline Serial Number & identifier for each weapon system. \\
\hline EROs & $\begin{array}{l}\text { Number of equipment repair orders opened/closed for given Serial } \\
\text { Number. }\end{array}$ \\
\hline EROs (critical) & $\begin{array}{l}\text { Number of critical equipment repair orders, EROs in which critical parts } \\
\text { were maintained, opened/closed for given Serial Number. }\end{array}$ \\
\hline EROs (deadline) & $\begin{array}{l}\text { Number of deadlining equipment repair orders opened/closed for given } \\
\text { Serial Number. }\end{array}$ \\
\hline Parts & $\begin{array}{l}\text { Total number of parts replaced for given Serial Number, based on } \\
\text { National Stock Numbers (NSNs). }\end{array}$ \\
\hline Parts (critical) & $\begin{array}{l}\text { Total number of critical parts replaced for given Serial Number based on } \\
\text { NSNs. Critical parts have a Criticality Code }=5 \text {. }\end{array}$ \\
\hline Unique & $\begin{array}{l}\text { Number of unique parts replaced for given Serial Number based on } \\
\text { NSNs. }\end{array}$ \\
\hline Uniqu & $\begin{array}{l}\text { r of unique critical parts replaced for given Serial Number based } \\
\text { Js. Critical parts have a Criticality Code }=5 \text {. }\end{array}$ \\
\hline Dow & $\begin{array}{l}\text { Number of days the given Serial Number was unavailable due to } \\
\text { maintenance. }\end{array}$ \\
\hline $\begin{array}{l}\text { Doy } \\
(\text { cri }\end{array}$ & $\begin{array}{l}\text { Similar to Category_M_Days_Deadlined. Number of } \\
\text { Serial Number was in a deadlined status due to critical ma }\end{array}$ \\
\hline $\begin{array}{l}\text { Downtime } \\
\text { (deadline) }\end{array}$ & $\begin{array}{l}\text { Number of days (usually Category_M_Days_Deadlined) the given Serial } \\
\text { Number was in a deadlined status due to maintenance. }\end{array}$ \\
\hline Cost & $\begin{array}{l}\text { Price associated with parts required for maintenance of given Serial } \\
\text { Number, which is taken from Supported Activities Supply System } \\
\text { (SASSY) and/or Federal Logistics Data (FEDLOG). }\end{array}$ \\
\hline Cost (critical) & $\begin{array}{l}\text { Price associated with critical parts required for maintenance of given } \\
\text { Serial Number, which is taken from SASSY/FEDLOG. }\end{array}$ \\
\hline MDBM & $\begin{array}{l}\text { Mean days between maintenance for given Serial Number based on } \\
\text { number of days Serial Number was available for service (i.e., Uptime) } \\
\text { divided by total EROs during specified period. }\end{array}$ \\
\hline
\end{tabular}




\begin{tabular}{|c|l|}
\hline Field & \multicolumn{1}{|c|}{ Description } \\
\hline MDBM (critical) & $\begin{array}{l}\text { Mean days between critical maintenance for given Serial Number based } \\
\text { on number of days Serial Number was available for service (i.e., Uptime } \\
\text { (critical)) divided by total EROs (critical) during specified period. }\end{array}$ \\
\hline $\begin{array}{c}\text { MDBM } \\
\text { (deadline) }\end{array}$ & $\begin{array}{l}\text { Mean days between deadlining maintenance for given Serial Number } \\
\text { based on number of days Serial Number was available for service (i.e., } \\
\text { Uptime (deadlining) divided by total EROs (deadlining) during } \\
\text { specified period. }\end{array}$ \\
\hline Avail. & $\begin{array}{l}\text { Availability of given Serial Number, a percentage of total time, is } \\
\text { cumulative calendar time Serial Number could be available for service } \\
\text { divided by time Serial Number was available for service } \\
\text { (Uptime/(Uptime + Downtime)). }\end{array}$ \\
\hline Avail. (critical) & $\begin{array}{l}\text { Critical availability of given Serial Number, a percentage of total critical } \\
\text { time, is cumulative critical calendar time Serial Number could be } \\
\text { available for service divided by critical time Serial Number was } \\
\text { available for service (Uptime (critical)/(Uptime (critical) + Downtime } \\
\text { (critical)). }\end{array}$ \\
\hline Avail. (deadline) \\
\hline $\begin{array}{c}\text { Deadlining availability of given Serial Number, a percentage of total } \\
\text { deadlining time, is cumulative critical calendar time Serial Number } \\
\text { could be available for service divided by deadlining time Serial Number } \\
\text { was available for service (Uptime (deadlining)/(Uptime (deadlining) } \\
\text { Downtime (deadlining)) }\end{array}$ \\
\hline Uptime & $\begin{array}{l}\text { Number of days the given Serial Number was available for operation and } \\
\text { not subject to maintenance. }\end{array}$ \\
\hline Uptime (critical) & $\begin{array}{l}\text { Number of days the given Serial Number was available for operation and } \\
\text { not subject to critical maintenance. }\end{array}$ \\
\hline $\begin{array}{c}\text { Uptime } \\
\text { (deadline) }\end{array}$ & $\begin{array}{l}\text { Number of days the given Serial Number was available for operation and } \\
\text { not subject to deadlining maintenance. }\end{array}$ \\
\hline
\end{tabular}




\section{LIST OF REFERENCES}

10 U.S.C. $\S 2460$ (2012).

10 U.S.C. $§ 2464$ (2012).

10 U.S.C. $§ 2474$ (2012).

10 U.S.C. $\S 3013$ (2010).

10 U.S.C. $§ 5013$ (2011).

10 U.S.C. $\S 8013$ (2010).

Anniston Army Depot. (2013a). Awards. Retrieved from http://www.anad.army.mil/awardsANAD.shtml

Anniston Army Depot. (2013b). Mission statement. Retrieved from http://www.anad.army.mil/missionANAD.shtml

Army Materiel Command. (2006). Public-private partnerships with industry [Presentation slides]. Retrieved from http://www.dtic.mil/ndia/2006munitions/davis.pdf

Capabilities Assessment Support Center. (2013, November 2). System operational effectiveness (SOE) user guide, version 1.0.1.3. Retrieved from https://merit.logcom.usmc.mil/casc/Help.do?help=mainHeadquartersUnitedStates

Curtin, N. P. (2001, May 22). Military aircraft: Cannibalizations adversely affect personnel and maintenance (GAO-01-693T) [Testimony]. Retrieved from http://www.gao.gov/products/GAO-01-693T

Davis, R. J., Jr. (2006, February 8). Public-private partnerships with industry. Presentation at Advance Planning Briefing to Industry (APBI). Retrieved from http://www.dtic.mil/ndia/2006munitions/davis.pdf

Department of Defense. (1984). DOD equipment maintenance program (DOD Directive 4151.16). Washington, DC: Author.

Department of Defense. (1986). Reliability centered maintenance requirements for naval aircraft, weapon systems and support (DOD MIL-STD-2173). Washington, DC: Author.

Department of Defense. (2010). Reliability centered maintenance process (MIL-STD3034). Washington, DC: Author. 
Dunn, R. J. (2013). The impact of a declining defense budget on combat readiness. Retrieved from The Heritage Foundation website: http://www.heritage.org/research/reports/2013/07/the-impact-of-a-decliningdefense-budget-on-combat-readiness

Government Accountability Office. (1993). Depot maintenance: Requirement to update maintenance analyses should be modified (GAO/NSIAD-93-163). Washington, DC: Author.

Headquarters Department of the Army. (2011). Operator's manual for tank, combat, fulltracked: 120 MM gun, M1A1 (TM 9-2350-264-10-1[Army]; TM 08953A-10/11[Marine Corps]). Washington, DC: Author.

Headquarters United States Marine Corps. (2003). Establishment of three levels of maintenance (MARADMIN 581/03). Retrieved from http://www.marines.mil/News/Messages/MessagesDisplay/tabid/13286/Article/11 $\underline{\text { 4300/establishment-of-three-levels-of-maintenance.aspx }}$

Headquarters United States Marine Corps. (2005). Marine Corps tank employment (Marine Corps Warfighting Publication [MCWP] 3-12). Washington, DC: Author.

Headquarters United States Marine Corps. (2009). Marine Corps total life cycle management (TLCM) of ground weapon systems, equipment and materiel (MCO 4000.57A). Washington, DC: Author.

Headquarters United States Marine Corps. (2013). Levels of maintenance (MARADMIN 159/13). Retrieved from http://www.marines.mil/News/Messages.aspx?Article=140301\&videoid=

Jane's Information Group. (2013). General Dynamics Land Systems M1/M1A1/M1A2 Abrams MBT. Retrieved from https://janes.ihs.com/CustomPages/Janes/DisplayPage.aspx?DocType=Reference \&ItemId $=+++1494282 \&$ Pubabbrev=JAFV

Military Sealift Command. (2013). Prepositioning. Retrieved from http://www.msc.navy.mil/PM3/

Moubray, J. (1997). Reliability-centered maintenance (2nd ed.). New York, NY: Industrial Press.

Nowlan, F. S., \& Heap, H. F. (1978). Reliability-centered maintenance (airline operations). Retrieved from http://search.proquest.com/docview/23174598?accountid=12702 
Office of Marine Corps Systems Command, Product Manager Tank Systems. (2012, September 2). Statement of work (SOW) for the rebuild of the MIA1 Main Battle Tank NSN 2350-01-087-1095 TAMCN E1888 ID\# 08953A (SOW-PMM14208953A-1/1). Quantico, VA: USMC.

Office of Marine Corps Systems Command, Product Manager Tank Systems. (2013, August 19). MIA1 Sustainment Maintenance Strategy [Presentation slides]. Quantico, VA: USMC.

Office of the Under Secretary of Defense for Acquisition, Technology, and Logistics. (2007). Condition based maintenance plus (CBM+) for materiel maintenance (DOD Instruction 4151.22). Washington, DC: Author.

Office of the Under Secretary of Defense for Acquisition, Technology, and Logistics. (2012a). Condition based maintenance plus $(C B M+)$ for materiel maintenance (DOD Instruction 4151.22). Retrieved from http://www.acq.osd.mil/log/mpp/policy/DODI415122p1.pdf

Office of the Under Secretary of Defense for Acquisition, Technology, and Logistics. (2012b). Reliability centered maintenance (DOD Manual 4151.22-M).

Washington, DC: Author.

Office of the Under Secretary of Defense for Logistics and Materiel Readiness. (2004). Maintenance of military materiel (DOD Directive 4151.18). Retrieved from http://www.dtic.mil/whs/directives/corres/pdf/415118h.pdf

Office of the Under Secretary of Defense for Logistics and Material Readiness. (2011, April). Product support manager guidebook. Washington, DC. Author.

Office of the Under Secretary of Defense for Logistics and Materiel Readiness. (2012, June 14). Metrics. Retrieved from http://www.acq.osd.mil/log $/ \mathrm{mr} / \mathrm{metrics.html}$

Peltz, E., Colabella, L. P., Williams, B., \& Boren, P. (2004, October). The effects of equipment age on mission critical failure rates: A study of M1 tanks (No. MR1789-A). Retrieved from RAND website: http://www.rand.org/content/dam/rand/pubs/monograph_reports/2005/MR1789.p df

Society of Automotive Engineers. (1999). Evaluation criteria for RCM processes (SAE JA1011). Warrendale, PA: Author.

Society of Automotive Engineers. (2002). A guide to the RCM standard (SAE JA1012). Warrendale, PA: Author.

United States Army Tank-Automotive and Armaments Command. (2013, September 18). Cost estimate request for FY14 unit funded cost and unit total cost [Memorandum]. Warren, MI: Department of the Army. 
United States Marine Corps. (1997). Inspection and evacuation criteria for tank, combat, full tracked, 120MM gun, M1A1, enclosure 1 (Technical Instruction 08953A14/9). Washington, DC: Author.

United States Marine Corps. (2012, January 23). Enterprise lifecycle maintenance program (MCO 4790.24). Retrieved from

http://community.marines.mil/news/publications/Documents/MCO\%204790.24.p df

United States Navy Air Systems Command. (2013). Introduction to reliability centered maintenance [Presentation slides]. Retrieved from www.navair.navy.mil/logistics/RCM/library/C1-1(Intro).ppt 


\section{INITIAL DISTRIBUTION LIST}

1. Defense Technical Information Center

Ft. Belvoir, Virginia

2. Dudley Knox Library

Naval Postgraduate School

Monterey, California 